\title{
Order Flow Information and Spot Rate Dynamics
}

\author{
Martin D.D. Evans ${ }^{(1)}$ and Dagfinn Rime ${ }^{(2)}$
}

April 2015

First Draft.

\begin{abstract}
This paper examines why order flows are empirically important drivers of spot exchange rate dynamics. We consider a decomposition for the depreciation rate that must hold in any model and show that order flows will appear as important proximate drivers when they convey significant incremental information about future interest rate differentials, risk premiums and/or long-run exchange rate levels (i.e., information that cannot be inferred from publicly observed variables). We estimate the importance of these incremental information flows for the EURNOK spot exchange rate using eight years of highquality, disaggregated, end-user order flow data collected by the Norges Bank.
\end{abstract}

Keywords: Exchange Rate Dynamics, Microstructure, Order Flow.

JEL Codes: F3; F4; G1.

Respective affiliations are: (1) Georgetown University, Department of Economics, Washington DC 20057 and NBER. Tel: (202) 687-1570 email: evansm1@georgetown.edu. and (2) BI Norwegian Business School and Norges Bank, Oslo, Norway. Tel: +47-46410507 email: dagfinn.rime@bi.no. 


\section{Introduction}

Macroeconomic models stress the role of interest rate variations in driving exchange-rate dynamics. Although researchers have long-recognized the existence of deviations from uncovered interest parity (UIP), macro variables determine exchange rates in many models via their impact on the expected future path of interest differentials in a manner consistent with UIP. ${ }^{1}$ By contrast, the empirical link between exchange rates and macro fundamentals via interest differentials appears rather weak. While Engel and West (2006), Engel, Mark, and West (2008) and Mark (2009) all find that changing expectations of Taylor-rule interest rates do have exchange-rate effects; overall, they account for a small fraction of exchange-rate variability over months and quarters (see Evans, 2011). More generally, the opaque empirical connection between exchange rates and macro fundamentals presents a problem for central banks trying to predict the effects of policy actions because their exchange-rate effects are potentially important for inflation and competitiveness. One factor contributing to this opaqueness is the difficulty in identifying expectations. The real-time information available to foreign exchange market participants is typically far richer than the information available to researchers or central bankers. So the failure to identify the macro factors that account for exchange rate movements may simply reflect the mis-measurement of expectations. In this paper we model expectations conditioned on information that more closely corresponds to the real-time information of market participants, and explore the implications for the link between macro fundamentals and exchange-rate movements.

We draw on recent research which applies the analytic tools of microstructure finance to exchange-rate modeling. Here exchange rates are determined via a trading process which aggregates information contained in individual currency transactions and facilitates the efficient sharing of risks across market participants. ${ }^{2}$ These micro-based models make a sharp empirical prediction about the proximate drivers of exchange rates: Insofar as currency orders entering the market contain dispersed (non-public) information about the prospective risk and returns on different currency-denominated securities, the market-wide transaction flows produced by these orders induce an adjustment in the equilibrium exchange rate. A large empirical literature supports this prediction across many currencies. ${ }^{3}$ In particular one measure of transaction flows, order flow (i.e., the net of buyer- and seller-initiated transaction volume), appears as the dominant empirical driver of exchange-rate changes over horizons ranging from a few minutes to a few months. We build on this empirical finding by including order flows along with other publicly-observed macro variables in the information set used to identify expectations in our model. We then examine the incremental information order flows convey about future interest rates and risk premia that ultimately determine the movements in exchange rates over macro-relevant horizons. Thus our analysis bridges the divide between the existing empirical literature linking order flows and exchange rates, and the traditional empirical literature linking exchange rates with macro fundamentals.

Our analysis is only made possible by the availability of high quality market-wide trading data that spans a long time period. In particular we use data collected by the Norwegian central bank, the Norges Bank, on currency transactions between the euro and Norwegian krone (EURNOK) over eight years starting in

\footnotetext{
${ }^{1}$ For example, in New Keynesian models exchange rates react to revisions in the expected future path for interest differentials implied by Taylor rules that characterize how central banks' respond to changing macro conditions. See Chinn (2012) for a recent overview of the literature.

${ }^{2}$ See Evans (2011) for a textbook discussion of these models.

${ }^{3}$ For recent surveys of the literature, see Osler (2009) and Evans and Rime (2012).
} 
October 2005. One distinctive feature of these data is that they capture a large fraction of total trading activity in the market, rather than transactions conducted by a single bank or group of market participants. As such, they provide us with the most precise data available on conditions known to market participants in real time. Earlier research reported in Evans (2010) and Evans and Lyons (2013) used several years of order flow data from a single large bank, while Rime, Sarno, and Sojli (2010a) examine a year's worth of marketwide data, and Froot and Ramadorai (2005) use the currency positions of a particular subset of market participants. We are fortunate that our data covers a period during which both the EURNOK exchange rate and macroeconomic conditions in Norway and the Euro-area varied significantly. Furthermore, The Norges Bank data includes information on the transactions made by different key groups of market participants: banks, financial non-bank organizations and non-financial firms. We use this feature of the data to more precisely estimate how real-time expectations of market participants affect the EURNOK exchange rate.

The empirical model we develop combines forecasts from Vector Autogressions (VARs) with an accounting identity that identifies all the factors driving the change in the log EURNOK rate (i.e., the depreciation rate) over any finite horizon. Importantly, this approach allows us to study how the incremental information conveyed by order flows contributes to the EURNOK depreciation rate without reference to a particular economic model (like a New Keynesian model). One drawback of this approach is that it limits detailed interpretation of our results. In particular, we cannot identify why order flow may contain significant incremental information concerning some variables and not others. However, since our data spans both the world financial crisis and the european debt crisis where central banks engaged in extraordinary policy measures, any attempt to estimate a structural model would undoubtedly required the imposition of wildly counterfactual assumptions about the conduct of monetary policy over a good portion of our data sample.

The model estimates deliver several striking results: First we find that order flows from both financial and non-financial end-users (i.e., non-banks) convey significant incremental forecasting power for the EURNOK depreciation rate over horizons ranging from one week to one year. In fact, the forecasting power of order flows peaks at close to 20 percent at 5 months. This finding clearly contradicts the notion that the exchangerate effects of order flows are only short-lived; lasting no more than hours or perhaps days. Second, we find that none of the forecasting power of the order flows comes from information they convey about future interest rates. They carry no significant incremental information beyond that contained in publicly observed macro variables which produce very stable interest rate forecasts over time. Consequently, like the studies cited above, we attribute little of the variation in depreciation rates to changing interest-rate expectations even when conditioning on order flows. Third, we find that the forecast power of order flows for depreciation rates arises from the information they carry about future excess returns on euro-area bonds; i.e., future risk premia. Moreover, unanticipated order flows produce revisions in expected future risk premia and the long-run exchange rate (ten years ahead) that together generate unexpected variations in the EURNOK rate. Finally, we show how revisions in these expectations contributed to the sizable movements in the EURNOK rate during the world financial crisis and european debt crisis.

Our analysis builds on two distinct strands of prior empirical exchange-rate research: one based on macro models (e.g., Engel and West 2006, Engel, Mark, and West 2008 and Mark, 2009), and one based on micro models that examines the role of order flow. The novel aspect of our work, relative to the macro models, is that we estimate conditional expectations driving the exchange rate using information on both order flows 
and macro variables to more closely approximate the information available to market participants in real time. In this respect our work is close to Froot and Ramadorai (2005) (hereafter F\&R) who use changes in institutional investors' currency holdings as an additional variable in a VAR-based exchange-rate model. However, our analysis differs from F\&R in several important ways: First, their model restricts the long-run behavior of exchange rates and is estimated for a group of currencies with a VAR that imposes numerous coefficient restrictions. In contrast, we impose no long-run restrictions on our VARs. Second, their data on changing currency positions does not measure market-wide order flow, which comprises the flows from many distinct groups of end-users, not just institutional investors. Earlier research (e.g., King, Sarno, and Sojli, 2010; Evans, 2010) shows that order flows from different end-users convey different information about future fundamentals and exchange rates. The Norges data allow us to check the robustness of our findings to different measures of market-wide order flow derived from the transactions of different end-user groups. Third, we examine how information conveyed by order flows affects deprecation rates over horizons ranging from one week to one year. This contrasts with F\&R who use their VAR model to focus on daily depreciation rates alone.

Early micro-based exchange-rate research focused on the contemporaneous links between exchange rates and order flows, and to a lesser extent on the forecasting power of order flows for future depreciation rates over short horizons. Our work is more closely related to later research that examines the information conveyed by order flows. In particular, Evans (2010) and Evans and Lyons (2013) examine whether order flows from end-users contain incremental (non-public) information about (unreported) current and future macro variables. Evans and Lyons (2013) find, for example, that the order flows in the EURUSD market have considerable incremental forecasting power for future GDP growth, inflation and M1 growth in the US and Germany. Insofar as these variables affect future monetary policy, we would expect order flows to have incremental forecasting power for future interest differentials. In a similar vein, Rime, Sarno, and Sojli (2010a) show that order flows have short-term forecasting power for specific macro data releases.

The remainder of the paper is organized as follows: The next section presents the model we use to identify how incremental information conveyed by order flow drives depreciation rates. We describe the Norges Bank data in Section 3. Our empirical results are presented in Section 4. Section 5 concludes.

\section{Depreciation Rates and Order Flow Information}

In micro-based models order flows affect currency prices because they contain price-relevant information to market participants (see, e.g. Evans, 2011). Here we present an empirical model that enables us to identify the type of information conveyed by order flows. Theoretically speaking, there are just three possibilities: (i) information concerning the future course of short-term interest rates, (ii) information about the future risk premia necessary to compensate market participants for the possibility of adverse future spot rate variations, and (iii) information concerning the long-run spot rate. While theoretical exchange-rate models place restrictions on the relative importance of these information flows, we use time series techniques to estimate their relative importance consistent with joint behavior of spot rates and other variables. This approach allows us to identify the type and importance of the information contained in order flows that gives rise to their effects on spot rates. 
We start with the definition of the expected log excess return on holding foreign currency between the periods $t$ and $t+1$ :

$$
\delta_{t}=\mathbb{E}_{t}^{\mathrm{D}} s_{t+1}-s_{t}+\hat{r}_{t}-r_{t},
$$

where $s_{t}$ is the log exchange rate (NOK/EUR). Here $r_{t}$ and $\hat{r}_{t}$ are the log home (Norway) and foreign (Euro) one period nominal interest rates and $\mathbb{E}_{t}^{\mathrm{D}}$ denotes expectations conditioned on information known to currency dealers at the start of period $t, \Omega_{t}^{\mathrm{D}}$. We refer to $\delta_{t}$ as the foreign exchange risk premium, although, strictly speaking, $\delta_{t}$ also contains a Jensen inequality term to account for the fact that we are dealing with log rather than gross returns. We distinguish between the information available to currency dealers and information that is publicly known below.

Next, we rewrite (1) as a difference equation in $s_{t}$ and solve forward $H$ periods. Applying the Law of Iterated Expectations to the resulting expression produces

$$
s_{t}=\mathbb{E}_{t}^{\mathrm{D}} \sum_{i=0}^{H-1}\left(\hat{r}_{t+i}-r_{t+i}\right)-\mathbb{E}_{t}^{\mathrm{D}} \sum_{i=0}^{H-1} \delta_{t+i}+\bar{s}_{t},
$$

where $\bar{s}_{t} \equiv \mathbb{E}_{t}^{\mathrm{D}} s_{t+H}$. We consider the implications of (2) for the $h$-period depreciation rate, $\Delta^{h} s_{t+h}=s_{t+h}-s_{t}$, where $h<H$. By definition, this rate equals the sum of expected depreciation rate, $\mathbb{E}_{t}^{\mathrm{D}} \Delta^{h} s_{t+h}$, and the $h$-period-ahead forecast error $s_{t+h}-\mathbb{E}_{t} s_{t+h}$; components that can be directly computed from (2) as

$$
\begin{aligned}
\mathbb{E}_{t}^{\mathrm{D}} \Delta^{h} s_{t+h} & =\mathbb{E}_{t}^{\mathrm{D}} \sum_{i=0}^{h-1}\left(r_{t+i}-\hat{r}_{t+i}\right)+\mathbb{E}_{t}^{\mathrm{D}} \sum_{i=0}^{h-1} \delta_{t+i} \quad \text { and } \\
s_{t+h}-\mathbb{E}_{t}^{\mathrm{D}} s_{t+h} & =-\left(\mathbb{E}_{t+h}^{\mathrm{D}}-\mathbb{E}_{t}^{\mathrm{D}}\right) \sum_{i=h}^{H+h-1}\left(r_{t+i}-\hat{r}_{t+i}\right)-\left(\mathbb{E}_{t+h}^{\mathrm{D}}-\mathbb{E}_{t}^{\mathrm{D}}\right) \sum_{i=h}^{H+h-1} \delta_{t+i}+\bar{s}_{t+h}-\mathbb{E}_{t}^{\mathrm{D}} \bar{s}_{t+h} .
\end{aligned}
$$

Substituting these expressions into the identity $\Delta s_{t+h}^{h}=\mathbb{E}_{t}^{\mathrm{D}} \Delta^{h} s_{t+h}+s_{t+h}-\mathbb{E}_{t}^{\mathrm{D}} s_{t+h}$ produces

$$
\begin{aligned}
& \Delta^{h} s_{t+h}=\mathbb{E}_{t}^{\mathrm{D}} \sum_{i=0}^{h-1}\left(r_{t+i}-\hat{r}_{t+i}\right)+\mathbb{E}_{t}^{\mathrm{D}} \sum_{i=0}^{h-1} \delta_{t+i} \\
&-\left(\mathbb{E}_{t+h}^{\mathrm{D}}-\mathbb{E}_{t}^{\mathrm{D}}\right) \sum_{i=h}^{H+h-1}\left(r_{t+i}-\hat{r}_{t+i}\right)-\left(\mathbb{E}_{t+h}^{\mathrm{D}}-\mathbb{E}_{t}^{\mathrm{D}}\right) \sum_{i=h}^{H+h-1} \delta_{t+i} \\
&+\bar{s}_{t+h},-\mathbb{E}_{t}^{\mathrm{D}} \bar{s}_{t+h} .
\end{aligned}
$$

Equation (4) identifies all the proximate factors that can drive the $h$-period depreciation rate. Importantly, this expression follows simply from the Law of Iterated Expectations and the definition of the risk premium in (1). It contains no assumptions about the behavior of interest rates, the expected long run spot rate, or anything else about the structure of the economy. Consequently, (4) provides us with a framework for studying why order flows affect the dynamics of depreciation rates without reference to a particular theoretical exchange-rate model.

Consider, first, the forecasting power of order flows. Evans and Lyons (2005b) and King, Sarno, and Sojli (2010) find that order flows have forecasting power for future deprecation rates over horizons ranging from one 
day to one month. Equation (4) tells us that this forecasting power must reflect a correlation between current order flows and expectations concerning the future path of interest rates and the risk premia, identified by the first two terms of the right-hand-side of the equation. In contrast, the strong contemporaneous correlation between deprecation rates and order flows reported in Evans and Lyons (2002) and many others, largely reflects the link between unexpected depreciation rates and order flows. This linkage is identified by the terms in the last two rows of (4). Unexpected order flows between periods $t$ and $t+h$ can only affect the $h$-period depreciation rate, $\Delta^{h} s_{t+h}$, insofar as they convey information that leads to revisions in forecasts for future interest rates, risk premia and the long-run exchange rate. ${ }^{4}$

We study the link between order flows and depreciation rates by examining the incremental effects of order flows on the expectations' terms on the right-hand-side of equation (4). To formalize this idea, we partition dealers' information, $\Omega_{t}^{\mathrm{D}}$, between public and market information, i.e. $\Omega_{t}^{\mathrm{D}}=\left\{\Omega_{t}^{\mathrm{P}}, \Omega_{t}^{\mathrm{M}}\right\}$. The $\Omega_{t}^{\mathrm{P}}$ information set comprises current and past values of publicly observable variables such as interest rates, spot rates and other macro variables, while observations on current and past currency transactions are contained in the market information set $\Omega_{t}^{\mathrm{M}}$. Actual dealers report that order flows represent the most informative form of trading information, so we assume that $\Omega_{t}^{\mathrm{M}}$ is spanned by current and past order flows. Thus order flows augment the public information available to dealers. And, since the trading decisions of dealers literally determine exchange rates, order flows must affect spot rates through the incremental information they convey to dealers.

We identify the incremental information conveyed by of order flow concerning any variable $\varkappa_{t}$ at horizon $i$ by the difference between the forecasts conditioned on $\Omega_{t}^{\mathrm{D}}$ and $\Omega_{t}^{\mathrm{P}}: \mathbb{E}_{t}^{\mathrm{D}} \varkappa_{t+i}-\mathbb{E}_{t}^{\mathrm{P}} \varkappa_{t+i} \equiv \mathbb{E}_{t}\left[\varkappa_{t+i} \mid \Omega_{t}^{\mathrm{D}}\right]-$ $\mathbb{E}_{t}\left[\varkappa_{t+i} \mid \Omega_{t}^{\mathrm{P}}\right]$. Applying this idea to equation (4) provides an information-centered perspective on the links between order flows and depreciation rates. For example, the forecasting power of current order flows for future depreciation rates, $\Delta^{h} s_{t+h}$, must arise because they contained incremental information concerning future interest differentials $\left(\mathbb{E}_{t}^{\mathrm{D}}-\mathbb{E}_{t}^{\mathrm{P}}\right) \sum_{i=0}^{h-1}\left(r_{t+i}-\hat{r}_{t+i}\right) \neq 0$, and/or risk premia $\left(\mathbb{E}_{t}^{\mathrm{D}}-\mathbb{E}_{t}^{\mathrm{P}}\right) \sum_{i=0}^{h-1} \delta_{t+i} \neq 0$. Similarly, we can study how the incremental information contained in unanticipated order flows contributed to spot rate movements. For example, the revisions in interest rate expectations that contribute to unexpected spot rate movements in the second line of (4) can be rewritten as

$$
\left(\mathbb{E}_{t+h}^{\mathrm{P}}-\mathbb{E}_{t}^{\mathrm{P}}\right) \sum_{i=h}^{H+h-1}\left(\hat{r}_{t+i}-r_{t+i}\right)+\left\{\left(\mathbb{E}_{t+h}^{\mathrm{D}}-\mathbb{E}_{t+h}^{\mathrm{P}}\right)-\left(\mathbb{E}_{t}^{\mathrm{D}}-\mathbb{E}_{t}^{\mathrm{P}}\right)\right\} \sum_{i=h}^{H+h-1}\left(\hat{r}_{t+i}-r_{t+i}\right) .
$$

Here the first term identifies the contribution of public news, while the second identifies the contribution of unexpected order flows observed by dealers between $t$ and $t+h$. Revisions in expectations concerning future risk premia and long-run exchange rate (i.e., the last two terms on the right-hand-side of 4) are examined in an analogous manner.

In our empirical implementation, we examine the informational role of order flows as the drivers of depreciation rates in weekly data for horizons $h$ ranging from one week to one year (i.e., $h=1, \ldots, 52$ ). To allow for the possibility that order flows may convey information about interest rates and risk premia well into the future, we set the horizon for the expected long-run spot rate at ten years (i.e. $H=520$ ). This means that we must estimate expectations for interest rates and risk premia up to ten years into the

\footnotetext{
${ }^{4}$ The last term represent news about long-run exchange rates, $\mathbb{E}_{t+h}^{\mathrm{D}} s_{t+h+H}-\mathbb{E}_{t}^{\mathrm{D}} s_{t+h+H}$.
} 
future. To accomplished this we use forecasts for two VARs. One includes spot rates, interest rates and other variables from the public information set, $\Omega_{t}^{\mathrm{P}}$. Forecasts from this VAR, denoted by $\hat{\mathbb{E}}_{t}^{\mathrm{P}} \varkappa_{t+i}$, are used to estimate the conditional expectations $\mathbb{E}_{t}^{\mathrm{P}} \varkappa_{t+i}$, for any variable $\varkappa_{t}$. The other VAR includes the same publicly observable variables and order flows. We use the forecasts from this VAR, denoted by $\hat{\mathbb{E}}_{t}^{\mathrm{D}} \varkappa_{t+i}$, to estimate $\mathbb{E}_{t}^{\mathrm{D}} \varkappa_{t+i}$.

We compute a set of variance ratios from the VAR forecasts that quantify the information convey by order flows over various horizons. First we compare the contributions of expected depreciation rates to the variance of actual depreciation rates. By definition, we can write the actual depreciation rate as $\Delta^{h} s_{t+h}=$ $\hat{\mathbb{E}}_{t}^{\mathrm{N}} \Delta^{h} s_{t+h}+\left(s_{t+h}-\hat{\mathbb{E}}_{t}^{\mathrm{N}} s_{t+h}\right)$ for $\mathrm{N}=\{\mathrm{D}, \mathrm{P}\}$. Multiplying both sides of this identity by $\Delta^{h} s_{t+h}$ and taking expectations produces

$$
\mathbb{V}\left(\Delta^{h} s_{t+h}\right)=\mathbb{C} \mathbb{V}\left(\hat{\mathbb{E}}_{t}^{\mathrm{N}} \Delta^{h} s_{t+h}, \Delta^{h} s_{t+h}\right)+\mathbb{C V}\left(s_{t+h}-\hat{\mathbb{E}}_{t}^{\mathrm{N}} s_{t+h}, \Delta^{h} s_{t+h}\right)
$$

where $\mathbb{V}($.$) and \mathbb{C V}(.,$.$) denote the variance and covariance, respectively. Dividing through by the variance$ gives

$$
1=\mathcal{R}_{\Delta s}^{\mathrm{E}}(h)+\mathcal{R}_{\Delta s}^{\mathrm{U}}(h)
$$

where

$$
\mathcal{R}_{\Delta s}^{\mathrm{E}}(h)=\frac{\mathbb{C V}\left(\hat{\mathbb{E}}_{t}^{\mathrm{N}} \Delta^{h} s_{t+h}, \Delta^{h} s_{t+h}\right)}{\mathbb{V}\left(\Delta^{h} s_{t+h}\right)} \quad \text { and } \quad \mathcal{R}_{\Delta s}^{\mathrm{U}}(h)=\frac{\mathbb{C V}\left(s_{t+h}-\hat{\mathbb{E}}_{t}^{\mathrm{N}} s_{t+h}, \Delta^{h} s_{t+h}\right)}{\mathbb{V}\left(\Delta^{h} s_{t+h}\right)} .
$$

Here $\mathcal{R}_{\Delta s}^{\mathrm{E}}(h)$ identifies the fraction of the variance in the $h$-period depreciation rate attributable to changes in expected depreciations rates conditioned on $\Omega_{t}^{\mathrm{N}}$ for $\mathrm{N}=\{\mathrm{D}, \mathrm{P}\}$, while $\mathcal{R}_{\Delta s}^{\mathrm{U}}(h)$ identifies the complementary ratio attributed to unexpected depreciation. These ratios are readily computed from the estimated VARs (see Appendix for details).

Comparing the $\mathcal{R}_{\Delta s}^{\mathrm{E}}(h)$ and $\mathcal{R}_{\Delta s}^{\mathrm{U}}(h)$ ratios from the two VARs provides information on the incremental forecasting power of order flows for future depreciation rates across horizons. To understand the source of order flow's forecasting power we also compute

$$
\begin{aligned}
\mathcal{R}_{r-\hat{r}}^{\mathrm{E}}(h) & =\frac{\mathbb{C V}\left(\hat{\mathbb{E}}_{t}^{\mathrm{N}} \sum_{i=0}^{h-1}\left(r_{t+i}-\hat{r}_{t+i}\right), \hat{\mathbb{E}}_{t}^{\mathrm{N}} \Delta^{h} s_{t+h}\right)}{\mathbb{V}\left(\hat{\mathbb{E}}_{t}^{\mathrm{N}} \Delta^{h} s_{t+h}\right)} \text { and } \\
\mathcal{R}_{\delta}^{\mathrm{E}}(h) & =\frac{\mathbb{C V}\left(\hat{\mathbb{E}}_{t}^{\mathrm{N}} \sum_{i=0}^{h-1} \delta_{t+i}, \hat{\mathbb{E}}_{t}^{\mathrm{N}} \Delta^{h} s_{t+h}\right)}{\mathbb{V}\left(\hat{\mathbb{E}}_{t}^{\mathrm{N}} \Delta^{h} s_{t+h}\right)} .
\end{aligned}
$$

Equation (3a) implies that $1=\mathcal{R}_{r-\hat{r}}^{\mathrm{E}}(h)+\mathcal{R}_{\delta}^{\mathrm{E}}(h)$ so these ratios identify the contribution of changing expectations concerning future interest differentials and those concerning the risk premia to the variance of expected depreciation rates. We compare these ratios computed from the two VARs to study the source of order flow's forecasting power for depreciation rates.

Unexpected variations in depreciation rates can be decomposed in an analogous manner. Equation (3b) 
implies that $1=\mathcal{R}_{r-\hat{r}}^{\mathrm{U}}(h)+\mathcal{R}_{\delta}^{\mathrm{U}}(h)+\mathcal{R}_{\bar{s}}^{\mathrm{U}}(h)$ where

$$
\begin{aligned}
\mathcal{R}_{r-\hat{r}}^{\mathrm{U}}(h) & =-\frac{\mathbb{C V}\left(\left(\hat{\mathbb{E}}_{t+h}^{\mathrm{N}}-\hat{\mathbb{E}}_{t}^{\mathrm{N}}\right) \sum_{i=h}^{H+h-1}\left(r_{t+i}-\hat{r}_{t+i}\right),\left(s_{t+h}-\hat{\mathbb{E}}_{t}^{\mathrm{N}} s_{t+h}\right)\right)}{\mathbb{V}\left(s_{t+h}-\hat{\mathbb{E}}_{t}^{\mathrm{N}} s_{t+h}\right)}, \\
\mathcal{R}_{\delta}^{\mathrm{U}}(h) & =-\frac{\mathbb{C V}\left(\left(\hat{\mathbb{E}}_{t+h}^{\mathrm{N}}-\hat{\mathbb{E}}_{t}^{\mathrm{N}}\right) \sum_{i=h}^{H+h-1} \delta_{t+i},\left(s_{t+h}-\hat{\mathbb{E}}_{t}^{\mathrm{N}} s_{t+h}\right)\right)}{\mathbb{V}\left(s_{t+h}-\hat{\mathbb{E}}_{t}^{\mathrm{N}} s_{t+h}\right)} \text { and } \\
\mathcal{R}_{\bar{s}}^{\mathrm{U}}(h) & =\frac{\mathbb{C V}\left(\left(\bar{s}_{t+h}-\hat{\mathbb{E}}_{t}^{\mathrm{N}} \bar{s}_{t+h}\right),\left(s_{t+h}-\hat{\mathbb{E}}_{t}^{\mathrm{N}} s_{t+h}\right)\right)}{\mathbb{V}\left(s_{t+h}-\hat{\mathbb{E}}_{t}^{\mathrm{N}} s_{t+h}\right)} .
\end{aligned}
$$

Here the ratios $\mathcal{R}_{r-\hat{r}}^{\mathrm{U}}(h), \mathcal{R}_{\delta}^{\mathrm{U}}(h)$ and $\mathcal{R}_{\bar{s}}^{\mathrm{U}}(h)$ identify the contributions of news concerning future interest differentials, risk premia and the long-run spot rate to the variance on expected depreciation rates, respectively. Again, we study the extent to which order flows convey this news by comparing the ratios computed from the two VARs.

The ratios described above provide evidence on the role of order flow over the entire sample period. In addition we trace how order flows contribute to the historical movements in the EURNOK spot rate. For this purpose we use the VARs to compute alternative estimates of the expected future path for interest differentials, the risk premium and the long-run spot rate; the terms identified on the right-hand-side of (2). Through this analysis we are able to identify particular episodes where it appears that the information conveyed by order flow was particularly important in driving the spot rate. It also provides graphic evidence on the persistence of order flows affects.

\section{Data Description and Characteristics}

This section describes the order flow and macro data used in the empirical analysis. Our sample period is limited by the availability of the order flow data collected by the Norges Bank, which started in October 2005. Although data on order flows and spot rates is available day-by-day, we conduct our empirical analysis with data sampled at a weekly frequency. Trading in the foreign exchange market is very opaque: there is no single trading venue and banks are not required to report their dealers' trading to financial regulators on an on-going basis. Consequently, dealers only learn about the market-wide order flow via their market interactions. Prior research (see e.g. Evans and Lyons (2005a) and Evans (2011)) indicates that the complete dissemination of information across the foreign exchange market can take hours or even days. Our approach assumes that (most) information concerning end-user orders flows during a week is disseminated across the market by the end of each week.

The focus of our analysis is the EURNOK rate. This is the most liquid currency pair involving the Norwegian krone (NOK). According to the Bank for International Settlements (BIS) 2013 Triennial Foreign Exchange survey, the daily spot trading volume in EURNOK was USD 11bn compared to USD 6.4bn for the USDNOK, the second most liquid currency pair. ${ }^{5}$ We use several macroeconomic time series to span

\footnotetext{
${ }^{5}$ These numbers are so-called net-net numbers, adjusted for both local and cross-border inter-dealer double-counting. The
} 
the real-time information set available to market participants. These include: (i) the one-week interest rate differential against the euro, (ii) the euro-area term spread between one year and one week bond yields, the Norwegian term spread between one year and one week bond yields, (iii) the weekly change in USDdenominated Brent oil price and the (iv) the change in Norwegian real estate prices. All of these macro variables, except the real estate prices, are measured at the end of each week. Weekly real estate prices are estimated by cubic interpolation of monthly data (the NEF price index) published by the Norwegian Association of Real Estate Agents. For the sake of parsimony, we use the interest rate to capture the public information in our benchmark analysis and then check that our results are robust to the addition of the oil and real estate price series. Descriptive statistics are reported in Table 1.

Table 1: Descriptive Statistics: Spot and Macro-variables

\begin{tabular}{lcrrr}
\hline \hline & Mean & Median & Std. Dev. & Skew. \\
\cline { 2 - 5 } & -1.046 & -3.974 & 48.493 & 0.742 \\
Depreciation rate & 1.129 & 1.360 & 0.619 & -0.726 \\
Interest diff & 0.772 & 0.740 & 0.348 & 0.230 \\
Term spread, NOK & 0.701 & 0.640 & 0.304 & 0.701 \\
Term spread, EUR & 19.257 & 40.830 & 200.703 & -0.482 \\
Oil price change & 6.298 & 5.401 & 15.263 & 0.444 \\
Real estate price change & \multicolumn{4}{c}{} \\
& \multicolumn{4}{l}{} \\
Notes: Descriptive statistics for weekly observations on main macro variables over October \\
2005 until end 2013, but excluding the financial crisis (full year from July 2008), making it \\
379 weekly observations. The depreciation rate, the oil price change and the real estate price \\
change is measured in yearly percentage (change in logs) return.
\end{tabular}

The proprietary data collected by the Norges Bank on transactions in the EURNOK market enable us to compare the information content of order flows and macroeconomic variables. Since October 2005 Norges Bank collects daily data on disaggregated transactions from all of the nordic banks that act as dealers in Norwegian krone. The participating banks (in alphabetic order) are Danske Bank, DNB, Handelsbanken, Nordea and SEB (see Meyer and Skjelvik, 2006, for a complete description). To capture the total flows of these banks, all transactions by branches of the banks are reported, no matter where in the world the transaction occurred. When measured over comparable periods, the transactions covered by Norges Bank's data account for approximately one third of the global EURNOK trading volume reported in the BIS 2013 survey. This difference in coverage reflects the fact that the Norges Banks does not collect data from some of the global banks, such as Deutsche Bank, UBS and Citigroup, who are active participants in the EURNOK market.

The foreign exchange market is structured as a two-tier market, where end-users of currency (firms and households) transact with intermediaries (banks) in the first tier, and then the intermediaries transact with each other in the second tier. ${ }^{6}$ Importantly, the intermediaries have limits (either self-imposed or by interdealer trading volumes are USD 4bn and USD 1.9bn for EURNOK and USDNOK, respectively. Among end-users the financial clients are most important, representing USD 6.3bn and USD 3.7bn. Trading in the USDNOK market to a large extent reflects the importance of Norwegian oil-revenues.

${ }^{6}$ This description is remains accurate despite structural changes in the foreign exchange market over the last 10 years. Furthermore, the distinction between, and importance of, end-users and intermediaries is unchanged. 
Figure 1: Disaggregated Trading Volume

(a) Other foreign banks

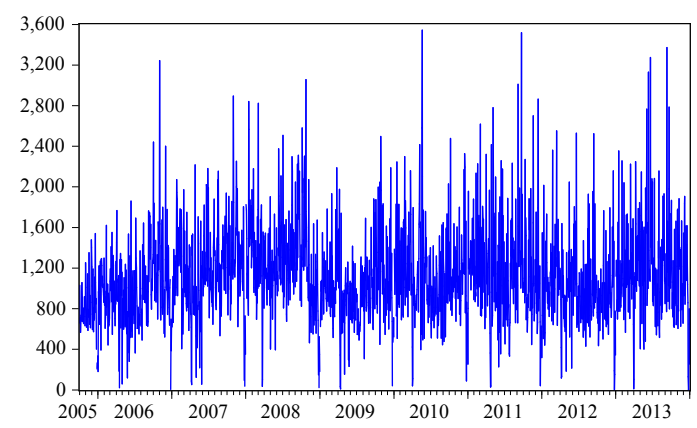

(c) Foreign Financial clients

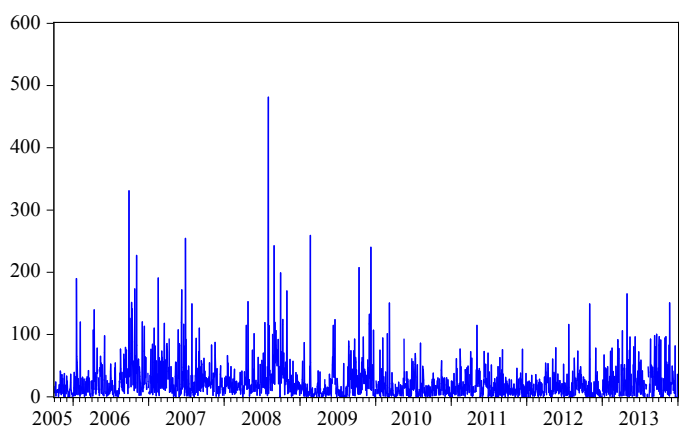

(e) Foreign Non-financial clients

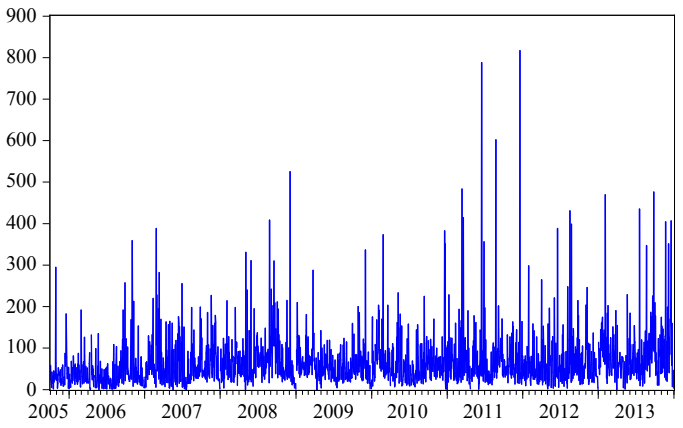

(g) Small Norwegian banks

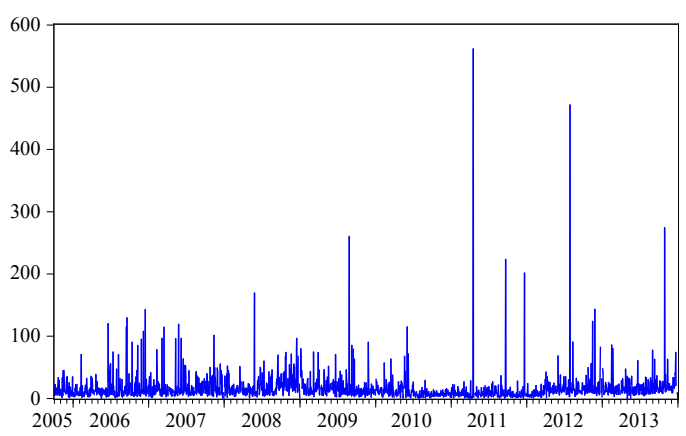

(b) Norges Bank

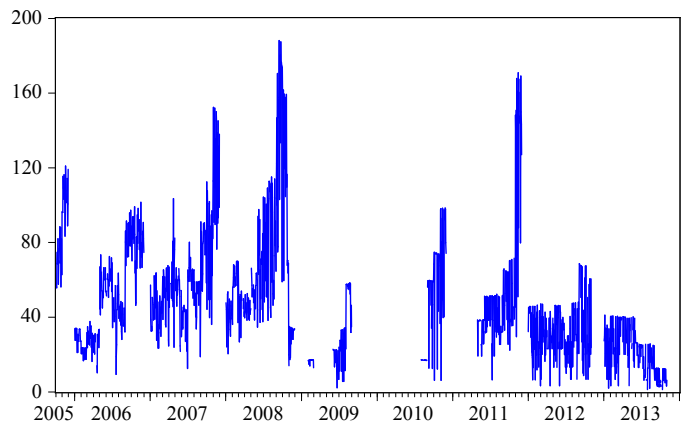

(d) Norwegian Financial clients

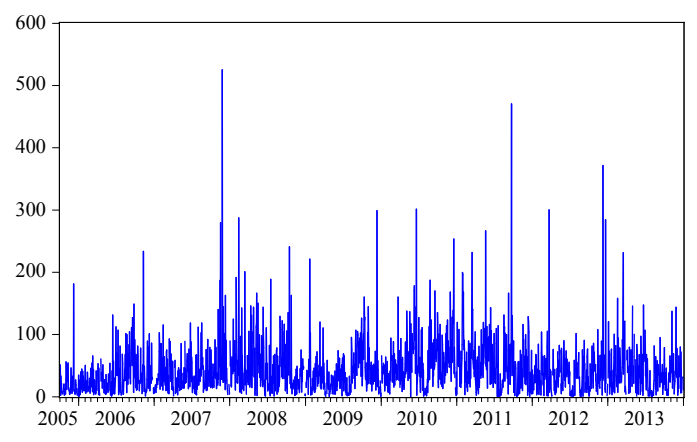

(f) Norwegian Non-financial clients

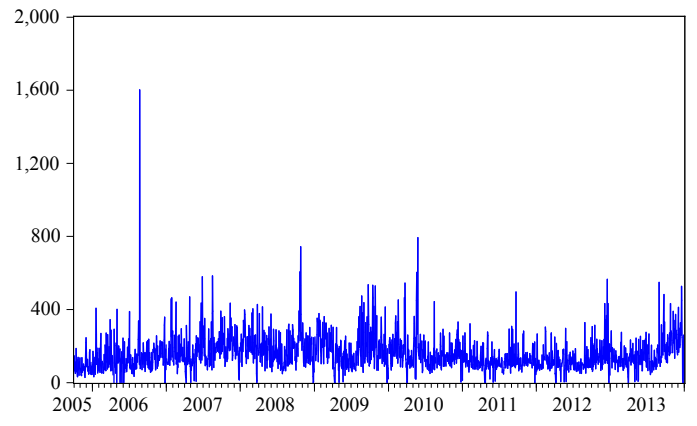

(h) Oil companies

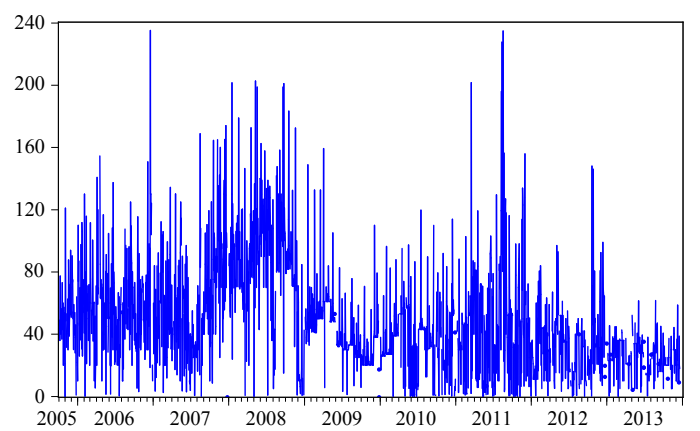

Notes: Trading volume by counter-party measured in millions of euros. Source: Norges Bank. 
regulation) on how much currency to hold overnight. Hence, they are truly intermediating the currency transactions by the firms and households. This structure means that the end-user order flows that we use in our analysis convey most of the non-public information reaching dealers from the rest of the economy, and that this is in fact the relevant part of the total end-user flows. The Norges Bank data contains the purchases and sales of nine different groups: (a) Other reporting banks (primarily as a check), (b) Small Norwegian banks (excluding the reporting banks), (c) Other foreign banks, (d) Norwegian financial endusers, (e) Foreign financial end-users, (f) Oil companies, (g) Norwegian non-financial end-users, (h) Foreign non-financial end-users, and (i) Norges Bank. Individual transactions are not reported to Norges Bank, so our raw data consists of daily aggregates of all transactions occurring during the day.

Figure 1 shows the development in the disaggregated EURNOK spot trading volumes (excluding the interreporter volumes). Overall, total volume rose more or less monotonically from the beginning of collection in 2005 until September 2008, it then contracted sharply as the world financial crisis unfolded. The highest average total daily volume of approximately EUR 3bn per day occurs during fall 2008. From January 2009 to the present the total volume stabilized and averaged approximately EUR $2 \mathrm{bn}$ per day. ${ }^{7}$

Microstructure theory emphasizes that different end-users may have diverse information concerning the state of the macroeconomy and differ in their motives for trading currencies. As a result, the information conveyed by order flow to dealers can vary according to the end-user counter-party in each transaction. The Norges Bank data allows us to examine the differences in the information conveyed by order flows insofar as it is reflected in the behavior of spot rates. Earlier research by Marsh and O'Rourke (2005) and Evans and Lyons (2013), finds that the main differences in the response of spot rates to order flows from different end-user groups appears between the flows of financial and non-financial end-users. Following this lead, we construct order flows from similarly defined groups of end-users. Specifically, the end-user groups shown in panels (a)-(d) of Figure 1 are used to construct financial end-user order flow (foreign and Norwegian financial flow, the flow of the Norges Bank, and the flow of non-reporting foreign banks), while the groups in panels (e)-(h) are used to construct non-financial end-user order flow (foreign and Norwegian non-financial flow, together with oil companies and small non-reporting Norwegian banks). Descriptive statistics for these order flows are provided in Table 2. Here we see that the financial order flows are more volatile than the non-financial flows, particularly the order flows from other foreign banks.

Indirect evidence on the diverse information conveyed by financial and non-financial order flows is provided in Table 3. Here we present the results from regressing the EURNOK depreciation rate on different combinations of interest rates and the two order flows defined above. The dependent variable in these regressions is the one-week change in log exchange rate, measured as a yearly return. The coefficient on order flow measures the impact of a one-standard deviation change in order flow. Heteroskedastic-robust standard errors are reported in parenthesis below the coefficient estimates. Consistent with many earlier studies, we find that the interest rates account for little of the variation in the depreciation rate. When order flows are absent, none of the coefficients on the interest rates are statistically significant at conventional levels and

\footnotetext{
${ }^{7}$ While we focus here on spot transactions, the Norges Bank data also cover other instruments, like swaps, forwards and options. Swaps continue to make up the lion's share of total transactions, accounting for 70 percent of total volume. Spot transactions make up 20 percent, and forwards make up the remaining 10 percent. As Meyer and Skjelvik (2006) note, trading in swap contracts comprise a large fraction of total volume but represent a small fraction of transactions. Over time, the composition of transactions across contracts has remained stable; with swap contracts accounting for 6 percent while spot and forward transactions account for 84 percent.
} 
Table 2: Descriptive statistics: End-user order flow

\begin{tabular}{|c|c|c|c|c|}
\hline & Mean & Median & Std.Dev. & Skew. \\
\hline $\begin{array}{l}\text { Financial flow } \\
\text { Other Foreign Banks } \\
\text { Norges Bank } \\
\text { Foreign Financial clients } \\
\text { Norwegian Financial clients }\end{array}$ & $\begin{array}{r}-0.676 \\
-2.332 \\
1.586 \\
-0.032 \\
0.101\end{array}$ & $\begin{array}{r}-0.953 \\
-2.241 \\
1.380 \\
0.001 \\
0.034\end{array}$ & $\begin{array}{l}7.130 \\
6.931 \\
1.450 \\
0.453 \\
0.728\end{array}$ & $\begin{array}{r}0.039 \\
-0.068 \\
0.928 \\
0.147 \\
1.589\end{array}$ \\
\hline $\begin{array}{l}\text { Non-financial } \\
\text { Foreign Non-Financial clients } \\
\text { Norwegian Non-Financial clients } \\
\text { Small Norwegian banks } \\
\text { Oil companies }\end{array}$ & $\begin{array}{r}-0.215 \\
-0.090 \\
1.359 \\
0.090 \\
-1.574\end{array}$ & $\begin{array}{r}-0.159 \\
-0.051 \\
1.210 \\
0.102 \\
-1.376\end{array}$ & $\begin{array}{l}2.538 \\
1.038 \\
1.896 \\
0.382 \\
1.065\end{array}$ & $\begin{array}{r}0.255 \\
2.119 \\
1.204 \\
-0.170 \\
-1.170\end{array}$ \\
\hline \multicolumn{5}{|c|}{$\begin{array}{l}\text { Notes: Descriptive statistics for weekly observations on aggregate financial and non-financial end-user order } \\
\text { flows, and their subgroups, from October } 2005 \text { until December } 2013 \text { (excluding the financial crisis, i.e., July } \\
2008 \text { to June 2009). Order flows are measured in 100s of millions of EUR. Financial end-user order flow } \\
\text { is based on the sum of Norwegian and foreign financial customers, non-reporting foreign banks and the } \\
\text { Norges Bank. Non-financial end-user order flow is based on the sum of Norwegian and foreign non-financial } \\
\text { end-users, oil-companies and small Norwegian banks. }\end{array}$} \\
\hline
\end{tabular}

the adjusted $R^{2}$ statistics are essentially zero. In contrast, the coefficients on either order flow measure are highly significant, and the adjusted $R^{2}$ statistics range from 0.36 to 0.40 . These findings are consistent with the notion that our end-user order flows convey information to dealers that is then impounded into spot exchange rates. Consistent with previous empirical findings (see, e.g., Marsh and O'Rourke 2005, and Evans and Lyons 2013) the sign of the impact of the two order flows are opposite of each other. When we combine both financial and non-financial end-user order flow in the same regression we see that it is the financial order flow that provides the strongest explanatory power.

Of course the impact of order flows on depreciation rates may reflect something other than just the impounding of information. For example, F\&R argue that the estimated impact of order flow could arise from temporary illiquidity effects or congestion. As transactions go through the market, they argue, currency prices move temporarily to allow the volumes to be transacted. One way to asses this view is to consider the long-term effects of order flows on the level of exchange rates. To this end we examine whether the log level of the EURNOK rate is cointegrated with the cumulated order flows from financial and non-financial end-users. We create two Vector Error Correction models (VECM), where each contain the log level of the EURNOK, together with the separate cumulative flows of the four end-user segments assigned to financial and non-financial groups, respectively (see Figure 1). This is done in order to create aggregate end-user flows as linear combinations of the underlying separate flows. Panel A of Table 4 reports Johansen Trace statistics for test of cointegration from the VECM's. These statistics provide strong evidence against the null hypothesis of no cointegration for the order flows from each group of end-users. In Panel B, we report tests for the presence of a unit root in the estimated error-correction terms (i.e. $s_{t}-\hat{\theta}^{\prime} x_{t}^{\text {CuM }}$, where $x_{t}^{\text {CUM }}$ is the vector of cumulative flows from the four end-user segments in the VECM, and [ $1-\hat{\theta}^{\prime}$ ] is the estimated 
Table 3: Price Impact Regressions

\begin{tabular}{|c|c|c|c|c|c|c|c|c|}
\hline & $(1)$ & $(2)$ & (3) & (4) & $(5)$ & $(6)$ & $(7)$ & $(8)$ \\
\hline Constant & $\begin{array}{c}3.662 \\
(0.813)\end{array}$ & $\begin{array}{l}10.776 \\
(1.714)\end{array}$ & $\begin{array}{c}3.401 \\
(0.832)\end{array}$ & $\begin{array}{l}-4.501 \\
(-0.986)\end{array}$ & $\begin{array}{l}1.747 \\
(0.338)\end{array}$ & $\begin{array}{c}-2.836 \\
(-0.422)\end{array}$ & $\begin{array}{l}1.565 \\
(0.361)\end{array}$ & $\begin{array}{l}-0.878 \\
(-0.158)\end{array}$ \\
\hline Interest diff. & $\begin{array}{l}-4.171 \\
(-1.213)\end{array}$ & $\begin{array}{l}-1.893 \\
(-0.511)\end{array}$ & $\begin{array}{c}-1.394 \\
(-0.449)\end{array}$ & $\begin{array}{l}1.637 \\
(0.459)\end{array}$ & $\begin{array}{l}1.209 \\
(0.385)\end{array}$ & $\begin{array}{c}4.166 \\
(1.059)\end{array}$ & $\begin{array}{c}-0.276 \\
(-0.086)\end{array}$ & $\begin{array}{c}2.447 \\
(0.746)\end{array}$ \\
\hline NOK spread & & $\begin{array}{c}-0.661 \\
(-0.065)\end{array}$ & & & $\begin{array}{l}16.352 \\
(2.158)^{*}\end{array}$ & $\begin{array}{l}9.936 \\
(1.133)\end{array}$ & & $\begin{array}{l}17.645 \\
(2.387)^{*}\end{array}$ \\
\hline EUR spread & & $\begin{array}{c}-13.094 \\
(-1.167)\end{array}$ & & & $\begin{array}{l}-19.791 \\
(-2.535)^{*}\end{array}$ & $\begin{array}{c}-17.414 \\
(-1.775)\end{array}$ & & $\begin{array}{l}-20.336 \\
(-2.682)^{* *}\end{array}$ \\
\hline $\begin{array}{l}\text { Financial } \\
\text { order flow }\end{array}$ & & & $\begin{array}{l}30.187 \\
(12.510)^{* *}\end{array}$ & & $\begin{array}{c}30.611 \\
(12.360)^{* *}\end{array}$ & & $\begin{array}{l}27.999 \\
(11.314)^{* *}\end{array}$ & $\begin{array}{l}28.308 \\
(11.105)^{* *}\end{array}$ \\
\hline $\begin{array}{l}\text { Non-financial } \\
\text { order flow }\end{array}$ & & & & $\begin{array}{l}-18.994 \\
(-5.618)^{* *}\end{array}$ & & $\begin{array}{l}-19.148 \\
(-5.516)^{* *}\end{array}$ & $\begin{array}{l}-4.315 \\
(-1.670)\end{array}$ & $\begin{array}{l}-4.649 \\
(-1.788)\end{array}$ \\
\hline $\operatorname{Adj} . R^{2}$ & 0.000 & 0.001 & 0.387 & 0.147 & 0.392 & 0.147 & 0.391 & 0.396 \\
\hline
\end{tabular}

Notes: The dependent variable is one-week change in log EURNOK spot exchange rate, measured as a yearly return. The coefficient on order flow measures the impact of a one-standard deviation change in order flow. Statistical significance at the 5 and 1 percent levels are denoted by "**" and "***", respectively.

cointegrating vector). The error-correction term is a generated regressor, so the p-values of the test statistics are not exact. However, combined, the ADF-test, which tests the null of a unit root, and the KPSS-test, which tests the null of absence of a unit root, clearly suggest that the error correction terms are not very persistent series. Taken together, Panel A and B indicate that end-user order flows have long-lasting effects on the EURNOK rate.

Figure 2 provides visual evidence. Here we plot the EURNOK rate $S_{t}$ and the fitted value implied by the cointegrating relation (assuming weak exogeneity) using financial order flow $\hat{S}_{t}=\exp \left(\hat{\theta}^{\prime} x_{t}^{\mathrm{CUM}}\right)$. Clearly, low frequency variations in a linear combination of cumulated order flows are closely associated with the long swings in the EURNOK rate. This finding in consistent with the results in Evans and Lyons (2002) for the USDDEM and USDJPY rates and in Chinn and Moore (2011) for the USDEUR and USDJPY rates.

We also examine the forecasting power of the end-user flows for future depreciation rates. We consider the returns from following a simple trading strategy based on the fitted values from a regression of next week's depreciation rate on a current predictor. The strategy involves holding a long (short) position in the euro when the fitted value from the regression implies an appreciation (depreciation) of the euro. Table 5 reports statistics on the returns from this strategy when different variables are used as predictors: The first two rows show results when the error-correction term involving different end-user order flows estimated from VECMs are used as predictors. The third and fourth rows show results from a carry trade strategy using the current interest differential and a momentum strategy using the depreciation rate as predictors, respectively. As the table clearly shows, the average returns from strategies using end-user order flows are substantially higher (but no more volatile) than those using the momentum or carry trade strategies. These findings are consistent with earlier results on the forecasting power of order flows (e.g., Evans and Lyons, 2005b; Rime, Sarno, and Sojli, 2010a). 
Table 4: Testing for Cointegration

\begin{tabular}{|c|c|c|c|c|}
\hline & \multicolumn{2}{|c|}{ Financial order flow } & \multicolumn{2}{|c|}{ Non-financial order flow } \\
\hline & Stat. & p-value & Stat. & p-value \\
\hline & \multicolumn{4}{|c|}{ A: Johansen cointegration test } \\
\hline $\mathrm{r}=0$ & 107.648 & 0.000 & 97.331 & 0.000 \\
\hline$r=1$ & 44.105 & 0.108 & 44.875 & 0.093 \\
\hline \multirow{2}{*}{$\mathrm{r}=2$} & 10.729 & 0.967 & 18.780 & 0.508 \\
\hline & \multicolumn{4}{|c|}{ B: Stationarity of Error-correction term $(z)$} \\
\hline $\mathrm{ADF}$ & -4.954 & 0.000 & -3.456 & 0.009 \\
\hline KPSS & 0.155 & $>0.100$ & 0.181 & $>0.100$ \\
\hline \multicolumn{5}{|c|}{$\begin{array}{l}\text { Notes: Panel A shows the trace-statistics and p-values for tests of cointegration rank } 0 \text { to } \\
2 \text { (further levels omitted to save space) from a VECM containing the log spot exchange } \\
\text { rate and the separate order flows used for the definition of financial and non-financial order } \\
\text { flow. Panel B presents tests for stationarity in the error-correction term from the VECMs. } \\
\text { The row labeled ADF shows statistics and p-values for the null of non-stationarity, while } \\
\text { the row labeled KPSS presents statistics and p-values for the null of stationarity. }\end{array}$} \\
\hline
\end{tabular}

Table 5: Descriptive Statistics for Returns from Predictive Regressions

\begin{tabular}{lcccc}
\hline \hline & & & & \\
Predictor & Mean & Median & Std. Dev. & Skew. \\
\hline & 6.473 & 6.026 & 48.028 & 0.159 \\
Financial order flow & 5.795 & 3.884 & 48.115 & 0.168 \\
Non-Financial order flow & 0.884 & 3.872 & 48.456 & -0.742 \\
Interest differential & 3.622 & 2.594 & 48.328 & 0.165 \\
Depreciation Rate & Notes: Table show annualized return from predictive regressions, going long EUR whenever the \\
EUR is predicted to appreciate and short otherwise. All regressions are for weekly return regressed \\
on one lag of predictor. For the flows the predictor is the error-correction term. The financial crisis \\
is excluded from the sample.
\end{tabular}

In summary the end-user order flows we construct from the Norges Bank data exhibit similar characteristics to the order flows examined in earlier studies: They have strong predictive and contemporaneous explanatory power for the EURNOK depreciation rate and when cumulated they account for most of the persistent variations in the level of EURNOK rate. Moreover, our data spans a longer and more recent time period, and covers a larger share of the total market than the data used in earlier studies (e.g., Froot and Ramadorai, 2005; Bjønnes, Rime, and Solheim, 2005; Evans and Lyons, 2013). ${ }^{8}$ In this respect it appears well-suited to studying the role order flows play in the determination of exchange rates over macro-relevant time spans.

\footnotetext{
${ }^{8}$ King, Sarno, and Sojli (2010) use a equally long dataset with similar coverage. Their sample ends in 2005.
} 
Figure 2: NOK/EUR $S_{t}$ and Cointegrated Cumulated Financial Order Flow

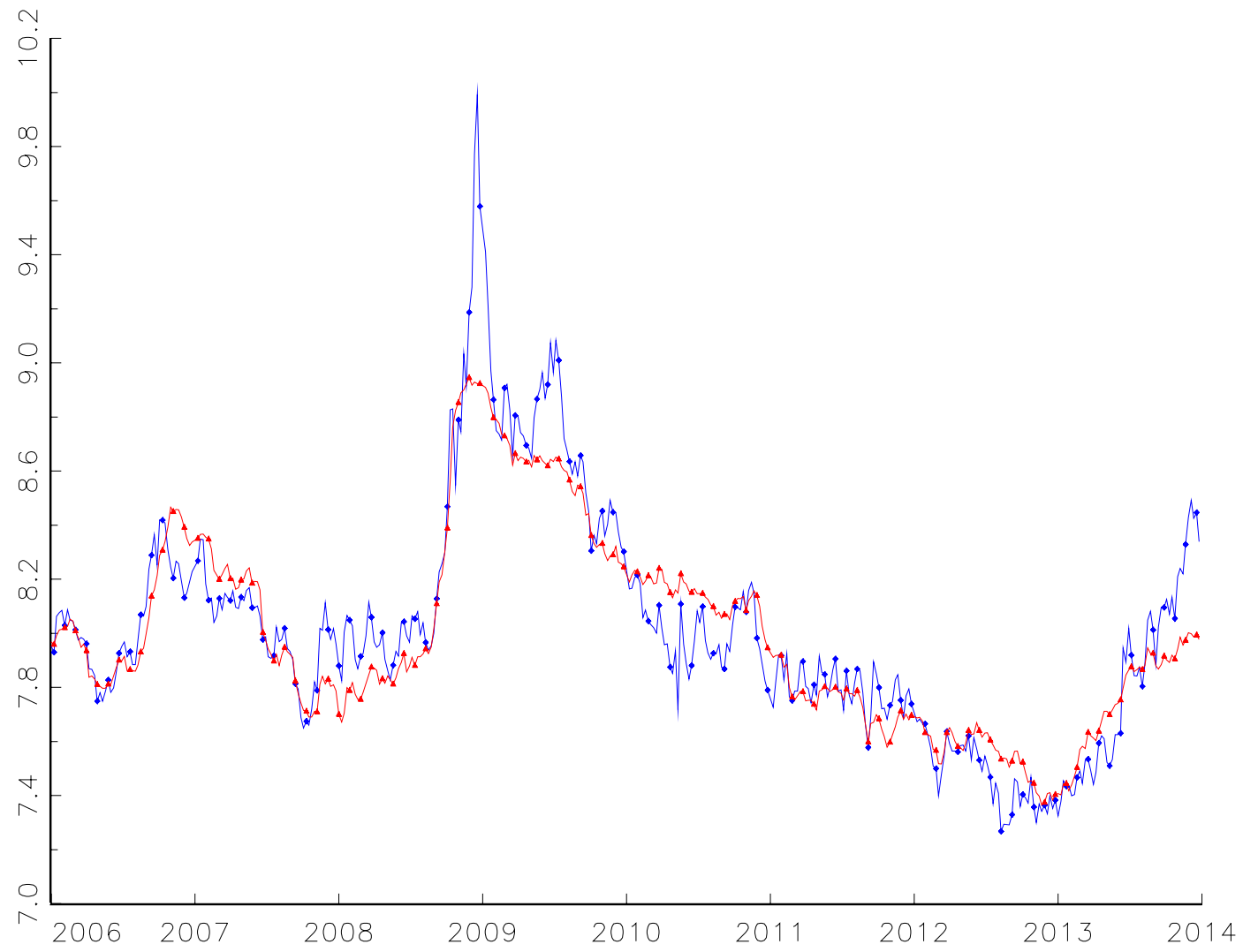

Notes: NOK/EUR spot rate $S_{t}$ : blue with diamonds. Estimates of cointegrating combination of cumulative financial order flows, red with bullets $\hat{S}_{t}=\exp \left(\hat{\theta}^{\prime} x_{t}^{\mathrm{CUM}}\right)$.

\section{Empirical Analysis}

This section presents the our main empirical findings - the estimated variance decompositions that quantify the incremental information contained in end-user order flows. These estimates are computed from two baseline VAR specifications: the VAR-P model that includes just publicly observed macro variables, and the VAR-D model that includes the same macro variables and the error-correction term involving the log exchange rate and financial end-user order flows. As we discuss in Section 4.4, the results we present here are robust to the inclusion of additional macro variables (specifically oil prices and real estate returns) and the use of different order flows (i.e. non-financial flows) in the error-correction term.

\subsection{Baseline VAR Estimates}

Our baseline VAR-P model includes the weekly depreciation rate $\Delta s_{t}$, the interest differential, $r_{t}-\hat{r}_{t}$, and both the NOK and EUR spreads between long and short-term nominal interest rates, $s p r_{t}$ and $\widehat{s p r}_{t}$. In addition to these variables, the base-line VAR-D model also includes the error-correction term $z_{t}=s_{t}-\hat{\theta}^{\prime} x_{t}^{\mathrm{CUM}}$, where $x_{t}^{\text {CUM }}$ is the vector of cumulated order flows from financial end-users. All of the VARs are estimated in weekly data from $3 / 10 / 2005$ to $30 / 12 / 2013$. Because this period covers the world financial crisis where 
exchange rates, interest rates and order flows exhibit very atypical time series characteristics, we do not use observations between 1/7/2008 and 30/6/2009 when estimating the VARs. Both our baseline VAR-P and VAR-D models are first-order - a choice that minimizes both the AIK and BIC statistics.

Table 6: Granger Causality Tests

\begin{tabular}{|c|c|c|c|c|c|}
\hline \multirow{2}{*}{$\begin{array}{l}\text { Forecasting } \\
\text { Variables }\end{array}$} & \multicolumn{5}{|c|}{ VAR Equations } \\
\hline & $\Delta s$ & $r-\hat{r}$ & $s p r$ & $\widehat{s p r}$ & $z$ \\
\hline $\begin{array}{l}\text { depreciation rate } \\
\Delta s\end{array}$ & $\begin{array}{c}0.426 \\
(0.514)\end{array}$ & $\begin{array}{l}10.332 \\
(0.001)\end{array}$ & $\begin{array}{l}7.259 \\
(0.007)\end{array}$ & $\begin{array}{c}4.006 \\
(0.045)\end{array}$ & $\begin{array}{c}2.144 \\
(0.143)\end{array}$ \\
\hline $\begin{array}{l}\text { interest diff } \\
r-\hat{r}\end{array}$ & $\begin{array}{c}0.056 \\
(0.812)\end{array}$ & $\begin{array}{l}1122.255 \\
(<0.001)\end{array}$ & $\begin{array}{c}6.152 \\
(0.013)\end{array}$ & $\begin{array}{c}4.711 \\
(0.030)\end{array}$ & $\begin{array}{c}0.210 \\
(0.647)\end{array}$ \\
\hline $\begin{array}{l}\text { NOK spread } \\
\text { spr }\end{array}$ & $\begin{array}{c}5.587 \\
(0.018)\end{array}$ & $\begin{array}{c}8.424 \\
(0.004)\end{array}$ & $\begin{array}{l}1025.564 \\
(<0.001)\end{array}$ & $\begin{array}{c}1.871 \\
(0.171)\end{array}$ & $\begin{array}{c}4.490 \\
(0.034)\end{array}$ \\
\hline$\frac{\text { EUR spread }}{s p r}$ & $\begin{array}{c}0.418 \\
(0.518)\end{array}$ & $\begin{array}{c}0.430 \\
(0.512)\end{array}$ & $\begin{array}{l}12.042 \\
(0.001)\end{array}$ & $\begin{array}{l}2274.311 \\
(<0.001)\end{array}$ & $\begin{array}{c}0.775 \\
(0.379)\end{array}$ \\
\hline $\begin{array}{l}\text { Error correction term } \\
z=s-\hat{\theta}^{\prime} x^{\mathrm{CUM}}\end{array}$ & $\begin{array}{c}17.042 \\
(<0.001)\end{array}$ & $\begin{array}{l}1.768 \\
(0.184)\end{array}$ & $\begin{array}{c}1.269 \\
(0.260)\end{array}$ & $\begin{array}{c}1.368 \\
(0.242)\end{array}$ & $\begin{array}{l}1175.251 \\
(<0.001)\end{array}$ \\
\hline
\end{tabular}

Notes: The table reports $\chi^{2}$ statistics for the null that the variables listed in the left-hand column have no forecasting power for the the variable listed at the top of each column. Heteroskedastic-consistent asymptotic p-values are reported in parenthesis below each test statistic.

Table 6 reports the results of Granger Causality tests for our baseline VAR-D model. Overall, the test statistics indicate a rich pattern of forecasting power among the variables. For each of the equations in the VAR there are at least two variables that appear to have statistically significant forecasting power. That is to say, none of the variables appears strictly exogenous. Notice, in particular, that both the error-correction term and NOK spread have forecasting power for the depreciation rate, and the NOK spread has forecasting power for the error correction term. In contrast, the interest differential has no significant forecasting power for the depreciation rate - a finding consistent with the failure of uncovered interest parity. Granger Causality tests for our baseline VAR-P model produce very similar findings to those reported in the first four rows and columns of Table 6 . These findings appear robust to our treatment of the world financial crisis. Including data from 1/7/2008 and 30/6/2009 when estimating the VAR produces very similar Granger Causality test statistics.

\subsection{Variance Ratios}

The plots in Figures 3 and 4 summarize our key findings concerning the role played by financial end-user order flows in the determination of the EURNOK depreciation rate. Here we show the variance ratios implied by our baseline VAR-P and VAR-D models for horizons of one to 52 weeks. The solid line in each panel 
plots the ratio implied by the estimated VAR-D model (i.e., the VAR with order flows), while the dashed line plots the ratio implied by the estimates of the VAR-P model (i.e., the VAR without order flows). The shaded area identifies the $90 \%$ confidence band computed from 5000 bootstrap replications of the VAR-D model.

The plots in Figure 3 show how the incremental information conveyed by financial end-user order flows contributes to the variations in expected depreciation rates. Recall that the $\mathcal{R}_{\Delta s}^{\mathrm{E}}(h)$ ratio measures the fraction of the variance in the $h$-period depreciation rate attributable to changes in expected depreciation conditioned on $\Omega_{t}^{\mathrm{N}}$ for $\mathrm{N}=\{\mathrm{D}, \mathrm{P}\}$. Panel (a) shows that these ratios are very different depending on whether the conditioning information set includes order flows. When order flows are not included, the estimated $\mathcal{R}_{\Delta s}^{\mathrm{E}}(h)$ ratio is close to zero across all horizons. This is not surprising because macro variables - like the interest rates spreads included in the VAR-P model - have little forecasting power for future depreciation rates across many currency pairs (see, e.g., Rossi, 2013), so the small values for $\mathcal{R}_{\Delta s}^{\mathrm{E}}(h)$ simply confirms their lack of forecasting power in the case of the EURNOK rate. In contrast, the values for $\mathcal{R}_{\Delta s}^{\mathrm{E}}(h)$ computed from the estimated VAR-D model are well above zero at all horizons, reaching a peak of approximately 0.25 at 19 weeks. This degree of forecasting power for depreciation rates is unusual. Prior studies find that order flows have forecasting power over horizons ranging from few days to a few weeks (see, e.g. Evans and Lyons, 2005b, Rime, Sarno, and Sojli, 2010b and King, Sarno, and Sojli 2010), well short of the peak forecasting horizon we find here. More generally, our estimates of $\mathcal{R}_{\Delta s}^{\mathrm{E}}(h)$ ratios imply that financial end-user order flows convey significant incremental information useful in forecasting the future EURNOK depreciation rate over a wide range of horizons.

The plots in panels (b) and (c) show where the incremental forecasting power of order flows originates. Panel (b) plots the estimated $\mathcal{R}_{r-\hat{r}}^{\mathrm{E}}(h)$ ratios which measure the contribution of changing expectations concerning future interest differentials to the variance of expected depreciation rates. Here we see that the estimates of $\mathcal{R}_{r-\hat{r}}^{\mathrm{E}}(h)$ implied by both the VAR-P and VAR-D model are close to zero across all horizons. Thus, the forecasting power of order flows for future depreciation rates does not originate from the information they contain concerning future interest differentials. It must therefore reflect information concerning the future path for the risk premia. This is confirmed by the estimates of $\mathcal{R}_{\delta}^{\mathrm{E}}(h)$ plotted in panel (c). Recall that this ratio measures the contribution of changing expectations concerning future risk premia to the variance of expected depreciation rates. Here we see that the values of $\mathcal{R}_{\delta}^{\mathrm{E}}(h)$ implied by the estimates of the VAR-D model are close to one across all horizons. Essentially all the forecasting power of order flows for depreciation rates reflects information in order flows that contributes to variations in expected future risk premia. ${ }^{9}$

The plots in Figure 3 have two further noteworthy features. First, they dispel the notion that information conveyed by order flow is only relevant for exchange rate determination over short horizons. As the plots in panel (a) clearly show, the forecasting power of order flow for future depreciation rates is not concentrated at horizons covering a couple of weeks. Second, order flows lack of incremental forecasting power for future interest differentials is consistent with the idea that relevant information concerning future short-term interest rates is quickly reflected in the current term structure. And, insofar as the interest differential is determined by the monetary policy actions of the ECB and Norges Bank, there is no evidence in our results that financial

\footnotetext{
${ }^{9}$ While the estimates of $\mathcal{R}_{\delta}^{\mathrm{E}}(h)$ implied by the VAR-P model are also close to one, macro variables contain little information that contributed to variations in expected future risk premia because the denominator in $\mathcal{R}_{\delta}^{\mathrm{E}}(h)$, the variance of expected depreciation rate, is very close to zero (as shown by the estimates of $\mathcal{R}_{\Delta s}^{\mathrm{E}}(h)$ from the VAR-P model).
} 


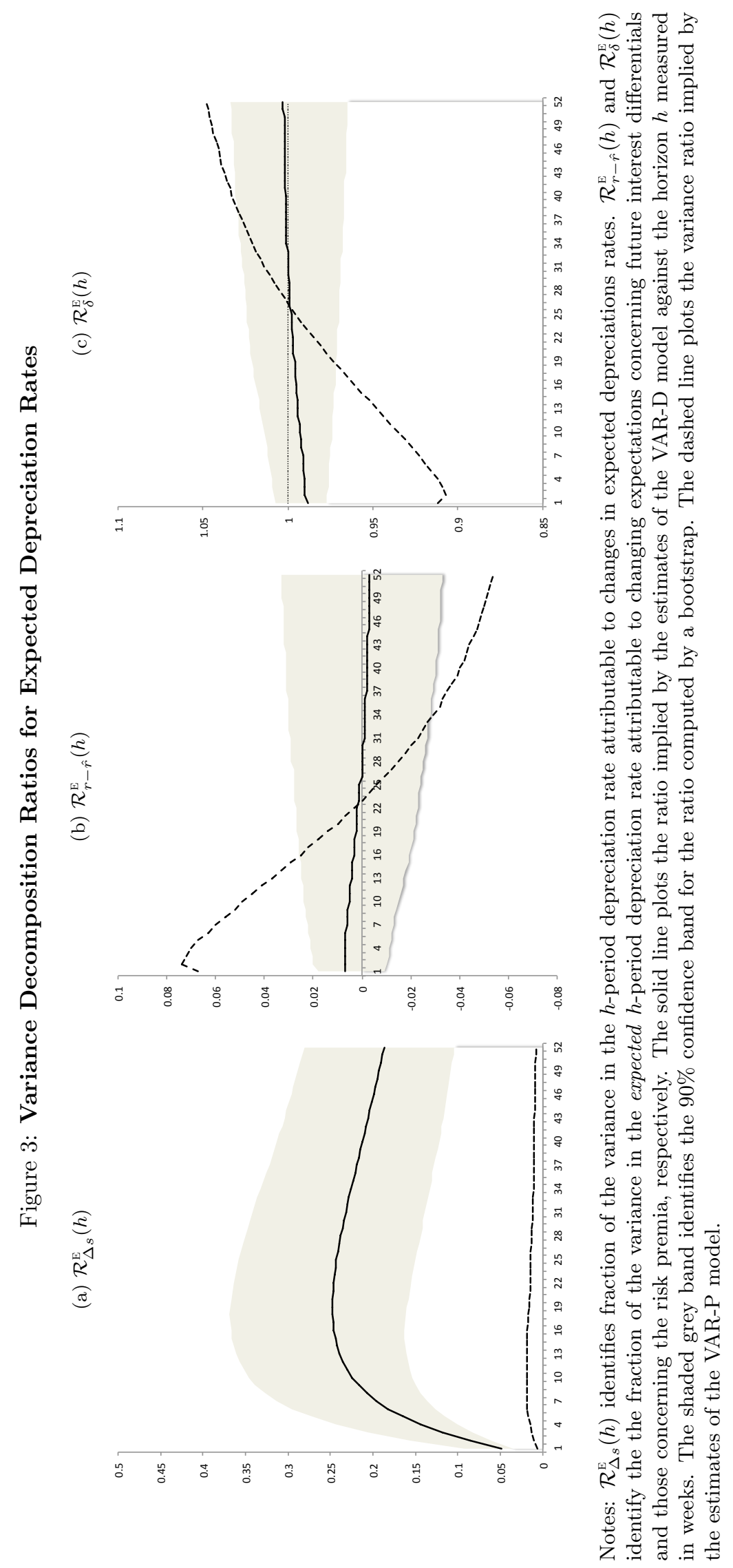


end-user order flows contain more precise information about future monetary policy than can be inferred from the euro-area and Norwegian term structures.

We next turn to the role played by unanticipated order flows. Figure 4 plots the $\mathcal{R}_{r-\hat{r}}^{\mathrm{U}}(h), \mathcal{R}_{\delta}^{\mathrm{U}}(h)$ and $\mathcal{R}_{\bar{s}}^{\cup}(h)$ ratios implied by the estimates of VAR-P and VAR-D models. These ratios measure the contributions of news concerning future interest differentials, risk premia and the long-run rate to the variance on unexpected depreciation rates, respectively. (Recall that the expected long run rate is defined as the log level of the exchange rate expected to prevail 10 years into the future.) By construction, $1=\mathcal{R}_{r-\hat{r}}^{\mathrm{U}}(h)+\mathcal{R}_{\delta}^{\mathrm{U}}(h)+\mathcal{R}_{\bar{s}}^{\mathrm{U}}(h)$, so these ratios provide a complete account of the factors driving unexpected variations in the EURNOK rate.

In panel (a) we see that the plots of $\mathcal{R}_{r-\hat{r}}^{\mathrm{U}}(h)$ based on the both the VAR-P and VAR-D model are close to zero at all horizons. This implies that revisions in the expected future interest differentials contribute little to unexpected variations in the depreciation rate. ${ }^{10}$ Recall from panel (b) of Figure 3 that variations in expected future interest rates also contribute little to the variations in expected depreciation rates. So, all in all, both the VAR-P and VAR-D model estimates imply that variations in interest differentials, expected or unexpected, are empirically unimportant drivers of the EURNOK rate. This is not to say that changes in prospective future interest differentials never have an effect. As we shall show below, there are occasions where they had a sizable effect. However, these occasions happen very rarely. Overall, variations in interest differentials contribute little to the dynamics of the EURNOK rate. This finding contradicts the long-standing notion that UIP links spot exchange rate dynamics to interest differentials. However, it is consistent with the findings in Evans (2012) for exchange rates across the G-7 countries.

The estimates of $\mathcal{R}_{\delta}^{\mathrm{U}}(h)$ and $\mathcal{R}_{\bar{s}}^{\cup}(h)$ plotted in panels (b) and (c) show what drives unexpected variations in the EURNOK rate. Consider first the dashed plots that identify the estimates ratios from the VAR-P model. Here we see that the estimates of $\mathcal{R}_{\delta}^{\mathrm{U}}(h)$ and $\mathcal{R}_{\bar{s}}^{\mathrm{U}}(h)$ are close to zero and one respectively. Macro variables contain little information about future interest differentials or risk premia, so unexpected changes in the current exchange rate, interest differential or term spreads must reflect an close to a one-to-one revision in the expected long run level of the exchange rate. Indeed, in the extreme case where the macro variables were completely irrelevant so that the log exchange rate followed a random walk, $\mathcal{R}_{\bar{s}}^{\mathrm{U}}(h)=1$ and $\mathcal{R}_{\delta}^{\mathrm{U}}(h)=\mathcal{R}_{r-\hat{r}}^{\mathrm{U}}(h)=0$ for all horizons $h$. The $\mathcal{R}_{\delta}^{\mathrm{U}}(h)$ and $\mathcal{R}_{\bar{s}}^{\mathrm{U}}(h)$ ratios derived from the VAR-D model are quite different. The estimates of $\mathcal{R}_{\delta}^{\mathrm{U}}(h)$ rise from approximately -0.8 to -0.3 while while the estimates of $\mathcal{R}_{\bar{s}}^{\mathrm{U}}(h)$ fall from approximately 1.8 to 1.3 as the horizon increases from one to 52 weeks. These estimates imply that a one percent unexpected depreciation over a week in the spot rate is typically associated with an upward revision in the long-run rate of close to 1.8 percent, and a downward revision in the expected future path for the risk premia of 0.8 percent. Unexpected depreciations over long horizons are associated with smaller forecast revisions.

The clear differences between the $\mathcal{R}_{\delta}^{\mathrm{U}}(h)$ and $\mathcal{R}_{\bar{s}}^{\mathrm{U}}(h)$ ratios implied by the VAR-P and VAR-D model estimates point to the role played by financial end-user order flows in driving unanticipated variations in the EURNOK rate. Unexpected order flow conveys news that leads to revisions in expectations about both the

\footnotetext{
${ }^{10} \mathrm{~F} \& \mathrm{R}$ also studied the source of exchange-rate variations in a VAR that included flows constructed from changes in institutional investors' currency holdings. They found that most of the variation unexpected in daily real depreciations rates was attributable to news concerning future risk premia rather than interest differentials (see, F\&R Table III). This finding is consistent with the small values for $\mathcal{R}_{r-\hat{r}}^{\mathrm{U}}(h)$ implied by our VAR-D model estimates at the $h=1$ week horizon because daily changes in real exchange rates are dominated by variations in nominal rates.
} 


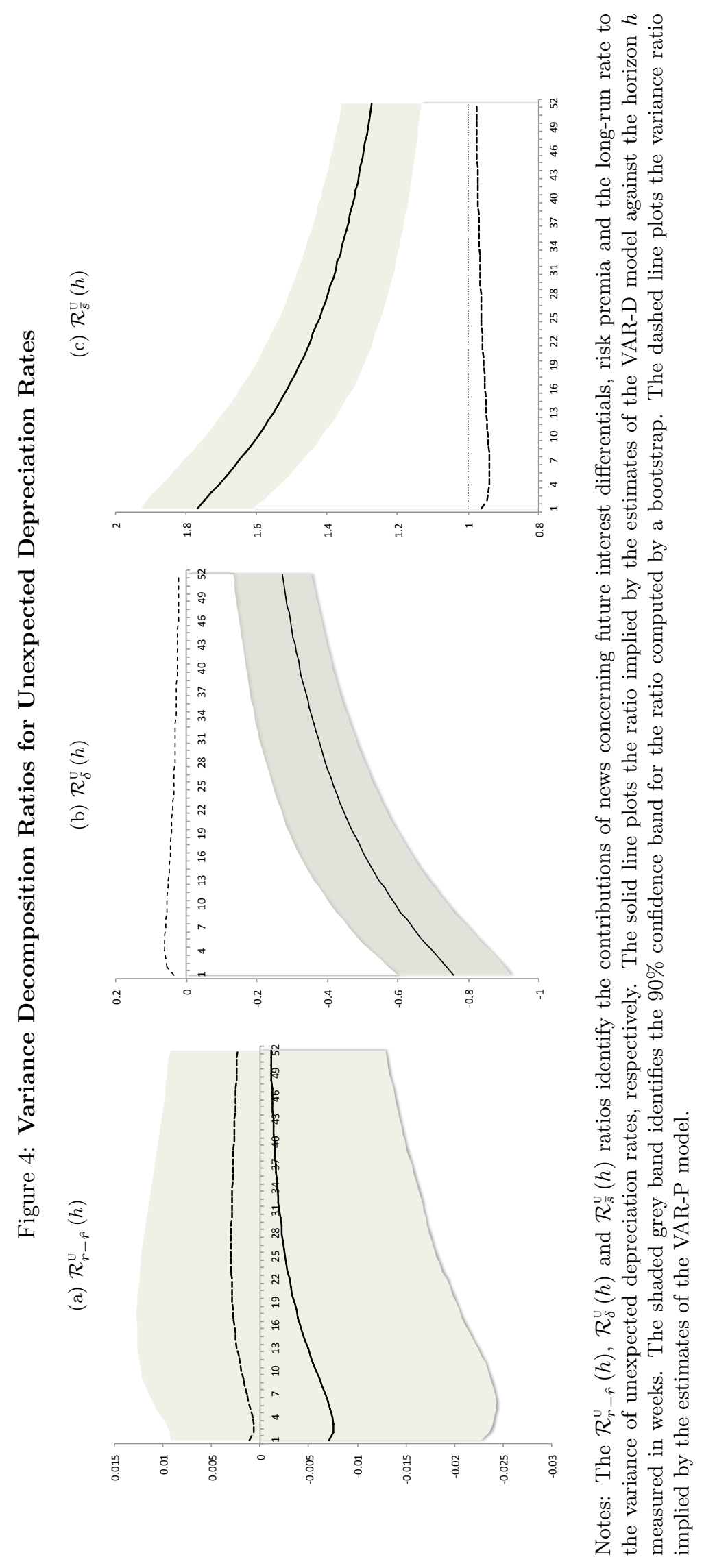


future risk premia and the long-run exchange rate. These revisions need to be in opposite directions because order flows contain little information relevant for forecasting future interest differentials so $\mathcal{R}_{\delta}^{\mathrm{U}}(h)+\mathcal{R}_{\bar{s}}^{\mathrm{U}}(h)$ must be close to one.

Table 7: Variance Ratios

\begin{tabular}{|c|c|c|c|c|c|c|c|c|}
\hline \multirow{2}{*}{ VAR } & \multicolumn{3}{|c|}{ VAR-D } & \multirow{2}{*}{$\frac{\text { VAR-P }}{\text { estimate }}$} & \multicolumn{3}{|c|}{ VAR-D } & \multirow{2}{*}{$\begin{array}{l}\text { VAR-P } \\
\text { estimate }\end{array}$} \\
\hline & estimate & std & $\mathrm{p}$-value & & estimate & std & p-value & \\
\hline & \multicolumn{4}{|c|}{ I: $\mathcal{R}_{\Delta s}^{\mathrm{E}}(h)$} & \multicolumn{4}{|c|}{ II: $\mathcal{R}_{\Delta s}^{\mathrm{U}}(h)$} \\
\hline horizon & & & & & & & & \\
\hline$h=1$ & 0.048 & $(0.017)$ & $5.2 \%$ & 0.006 & 0.952 & $(0.017)$ & $94.8 \%$ & 0.994 \\
\hline 4 & 0.144 & $(0.044)$ & $1.6 \%$ & 0.015 & 0.856 & $(0.044)$ & $98.4 \%$ & 0.985 \\
\hline 12 & 0.235 & $(0.060)$ & $0.9 \%$ & 0.019 & 0.765 & $(0.060)$ & $99.1 \%$ & 0.981 \\
\hline 26 & 0.241 & $(0.062)$ & $1.0 \%$ & 0.014 & 0.759 & $(0.062)$ & $99.0 \%$ & 0.986 \\
\hline \multirow[t]{2}{*}{52} & 0.187 & $(0.053)$ & $1.2 \%$ & 0.008 & 0.813 & $(0.053)$ & $98.8 \%$ & 0.992 \\
\hline & \multicolumn{4}{|c|}{ III: $\mathcal{R}_{r-\hat{r}}^{\mathrm{E}}(h)$} & \multicolumn{4}{|c|}{$\mathrm{IV}: \mathcal{R}_{\delta}^{\mathrm{E}}(h)$} \\
\hline 1 & 0.007 & $(0.009)$ & $76.7 \%$ & 0.067 & 0.988 & (0.009) & $22.6 \%$ & 0.912 \\
\hline 4 & 0.007 & $(0.010)$ & $71.6 \%$ & 0.070 & 0.990 & $(0.010)$ & $24.4 \%$ & 0.912 \\
\hline 12 & 0.005 & $(0.012)$ & $60.7 \%$ & 0.041 & 0.994 & $(0.013)$ & $35.4 \%$ & 0.944 \\
\hline 26 & 0.000 & $(0.016)$ & $52.6 \%$ & -0.009 & 0.999 & $(0.017)$ & $44.5 \%$ & 0.999 \\
\hline \multirow[t]{2}{*}{52} & -0.003 & $(0.020)$ & $48.7 \%$ & -0.054 & 1.003 & $(0.021)$ & $49.0 \%$ & 1.048 \\
\hline & \multicolumn{4}{|c|}{$\mathrm{V}: \mathcal{R}_{\delta}^{\mathrm{U}}(h)$} & \multicolumn{4}{|c|}{$\mathrm{VI}: \mathcal{R}_{\bar{s}}^{\mathrm{U}}(h)$} \\
\hline 1 & -0.759 & $(0.097)$ & $100.0 \%$ & 0.036 & 1.766 & $(0.096)$ & $0.0 \%$ & 0.963 \\
\hline 4 & -0.699 & $(0.101)$ & $100.0 \%$ & 0.060 & 1.706 & (0.101) & $0.0 \%$ & 0.940 \\
\hline 12 & -0.562 & (0.099) & $100.0 \%$ & 0.052 & 1.567 & $(0.099)$ & $0.0 \%$ & 0.946 \\
\hline 26 & -0.411 & $(0.086)$ & $100.0 \%$ & 0.035 & 1.413 & $(0.087)$ & $0.0 \%$ & 0.962 \\
\hline 52 & -0.272 & $(0.068)$ & $100.0 \%$ & 0.021 & 1.273 & $(0.068)$ & $0.0 \%$ & 0.976 \\
\hline
\end{tabular}

Notes: The variance ratio shown at the top of each panel is reported in the columns headed "estimate" based on either the VAR-D model (left-hand column) or VAR-P model (right-hand column). Standard errors for the VAR-D ratios are shown in parentheses based on 5000 bootstrap replications. The columns headed by "p-value" report the fraction of the bootstrap replications where the ratio computed from estimates of the VAR-P model was larger than the ratio computed from estimates of the VAR-D model.

Table 7 provides statistical evidence that compliments the plots in Figures 3 and 4 . The left-hand columns in each block report the values of the ratios (at select horizons $h$ ) implied by the VAR-D model, together with standard errors computed from the bootstrap. The right-hand columns report the p-value for the null that the ratio implied by VAR-P model estimates is larger than the ratio from the VAR-D model. The p-values are computed from the empirical distribution of the bootstrap. They quantify the differences between solid and dashed plots of the variance ratios shown in Figures 3 and 4 .

The statistics for the $\mathcal{R}_{\Delta s}^{\mathrm{E}}(h)$ and $\mathcal{R}_{\Delta s}^{\mathrm{U}}(h)$ shown in panels I and II confirm that financial end-user flows contained a statistically significant amount of incremental information concerning the future EURNOK depreciation rate at all horizons beyond a week. (Since $1=\mathcal{R}_{\Delta s}^{\mathrm{E}}(h)+\mathcal{R}_{\Delta s}^{\mathrm{U}}(h)$ by definition, the standard errors are the same and the p-values sum to one across the two panels.) In contrast, panels III and IV show 
that there are no statistically significant differences between the $\mathcal{R}_{r-\hat{r}}^{\mathrm{E}}(h)$ and $\mathcal{R}_{\delta}^{\mathrm{E}}(h)$ ratios implied by the VAR-P and VAR-D models estimates. Although the models imply very different degree of forecastability for future deprecation rates, all the forecasting power reflects changing expectations concerning future risk premia. Finally, the statistics in panels V and VI confirm that the differences between the implications of the VAR-P and VAR-D model estimates for the $\mathcal{R}_{\delta}^{\mathrm{U}}(h)$ and $\mathcal{R}_{\bar{s}}^{\mathrm{U}}(h)$ ratios plotted in Figure 4 are highly statistically significant.

In summary, our estimates of the baseline VAR-D and VAR-P models clearly show that financial enduser order flows convey an economically and statistically significant amount of incremental information concerning the future behavior of the EURNOK depreciation rate; information beyond that contained in current Euro-area and Norwegian interest rates. Moreover, this information is almost exclusively related to the future behavior of the risk premia rather than interest differentials. We also find that unexpected order flows contribute significantly to the unpredictable variations in the EURNOK rate because they convey information that produces sizable revisions in expected future path of the risk premia and long-run exchange rate.

\subsection{Historical Contributions}

The variance ratios examined above provide measures of the incremental information conveyed by order flow measured over the whole sample period. Of course, the actual information conveyed by order flow varies week-by-week. To examine these variations, we compare the historical paths for the expected long run exchange rate and the present values of future interest differentials and risk premia implied by the VAR-P and VAR-D model estimates.

The upper panel in Figure 5 plots the path of the EURNOK rate with the estimates of the expected long-run rate based on the VAR-P and VAR-D models: $\bar{S}_{t}^{\mathrm{N}}=\exp \left(\bar{s}_{t}^{\mathrm{N}}\right)$ for $\mathrm{N}=\{\mathrm{P}, \mathrm{D}\}$, respectively. Recall that $\bar{s}_{t}^{\mathrm{N}}$ is the expected value of the $\log$ exchange rate ten years into the future. So vertical differences between the plotted paths for $\bar{S}_{t}^{\mathrm{D}}$ and $\bar{S}_{t}^{\mathrm{P}}$ quantify the impact of the information conveyed by order flow for these long-term expectations. These distances vary in size throughout the sample period. For example, the distances are generally small before the start of 2008, during 2011 and the first six months of 2013. At other times, most notably at the start of 2009, there are sizable differences between the estimates.

The lower panel of Figure 5 provides another perspective. Here we plot $\bar{s}_{t}^{\mathrm{D}}-s_{t}$ and $\bar{s}_{t}^{\mathrm{P}}-s_{t}$, which are the expected ten-year depreciation rates implied by the VAR-D and VAR-P model estimates. These plots exhibit three noteworthy features. First, the graphs display significant variations, ranging between -0.8 and 0.4 percent per year. Both the VAR-P and VAR-D model estimates imply that the EURNOK rate exhibits far more complex dynamics than a simple random walk. Second, the plots for $\bar{s}_{t}^{\mathrm{D}}-s_{t}$ and $\bar{s}_{t}^{\mathrm{P}}-s_{t}$ clearly indicate episodes where the information in order flow materially affected long-run expectations. In addition to the start of 2009, the differences between the plots in late 2007, 2010, 2012 and late 2013 all identify episodes where information in order flows concerning the long-run level for the EURNOK appears to have been economically important. Finally, notice that some of these episodes last for many months. If the information conveyed by order flow about the long-run EURNOK rate were quickly impounded in interest rates, differences between $\bar{s}_{t}^{\mathrm{D}}-s_{t}$ and $\bar{s}_{t}^{\mathrm{P}}-s_{t}$ would be short-lived. By contrast, the persistent differences between the plots for $\bar{s}_{t}^{\mathrm{D}}-s_{t}$ and $\bar{s}_{t}^{\mathrm{P}}-s_{t}$ indicate that the information conveyed by order flow does not 
disseminate widely beyond the EURNOK market.

Figure 5: Long-Run Exchange Rate Expectations

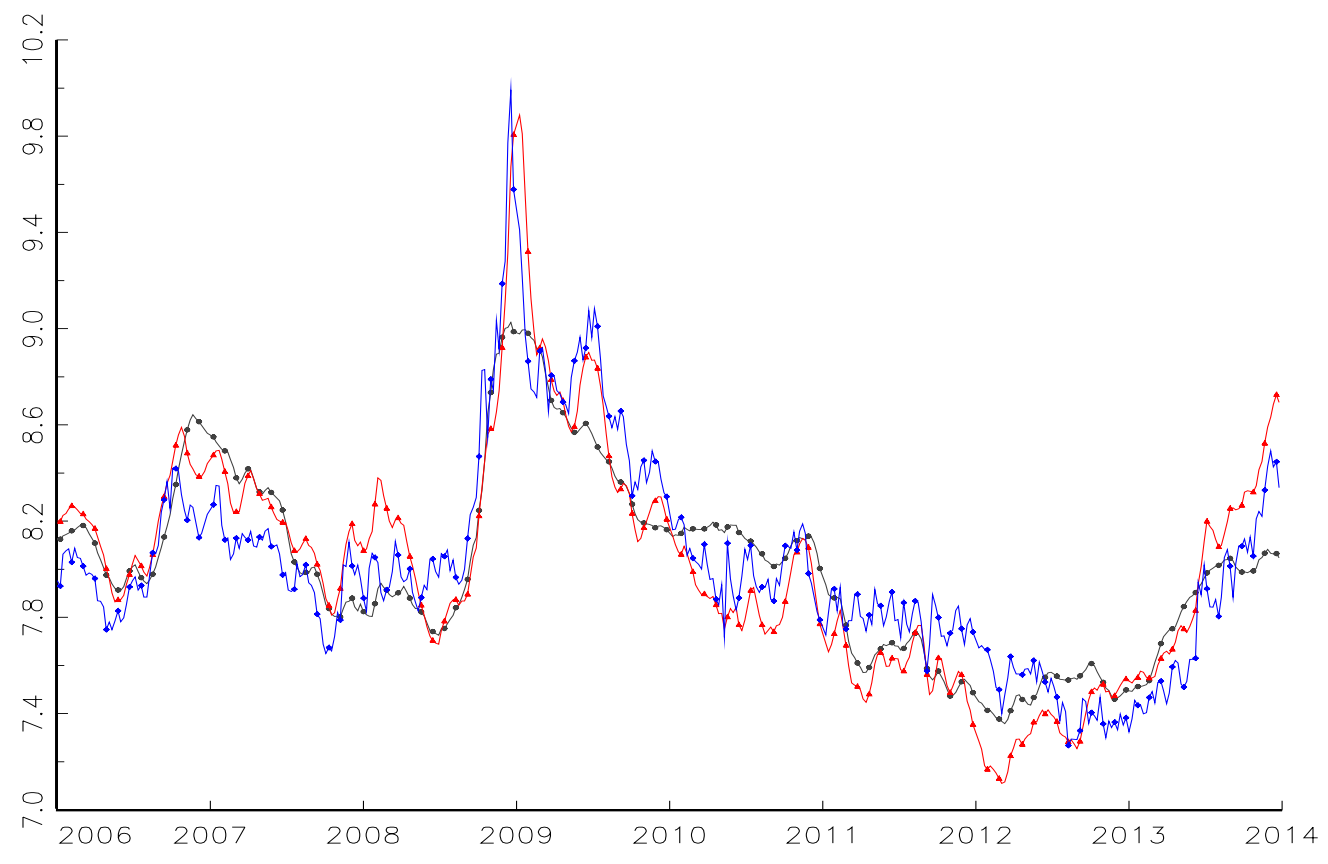

A: NOK/EUR exchange rate $S_{t}$ : blue with diamonds. Estimates of the long run rate $\bar{S}_{t}=\exp \left(\bar{s}_{t}\right)$ based on the estimates of VAR-D, $\bar{S}_{t}^{\mathrm{D}}$ : black with bullets, and estimates based on VAR-P, $\bar{S}_{t}^{\mathrm{P}}$ : red with triangles. All series are 4 -week moving averages.

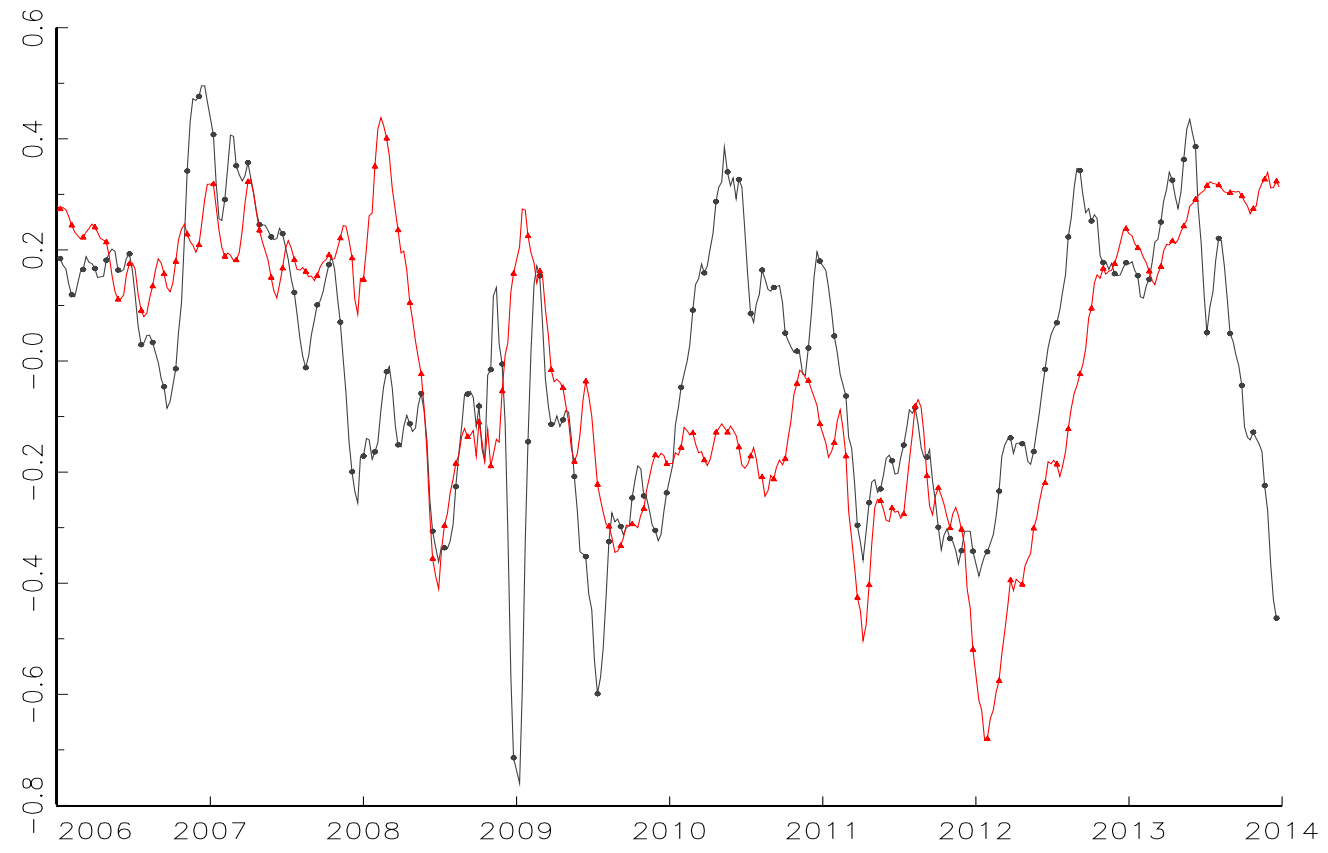

B: Long run expected depreciation rate for NOK/EUR (measured in percent per year). Estimates using order flow, computed as $\bar{s}_{t}^{\mathrm{D}}-s_{t}$, shown as black with bullets; estimates using public information, computed as $\bar{s}_{t}^{\mathrm{P}}-s_{t}$, shown as red with triangles. All series are 4-week moving averages. 
The expected long run depreciation rate in our models is given by

$$
\bar{s}_{t}^{\mathrm{N}}-s_{t}=\hat{\mathbb{E}}_{t}^{\mathrm{N}} \sum_{i=0}^{519}\left\{r_{t+i}-\hat{r}_{t+i}\right\}+\hat{\mathbb{E}}_{t}^{\mathrm{N}} \sum_{i=0}^{519} \delta_{t+i}
$$

for $\mathrm{N}=\{\mathrm{D}, \mathrm{P}\}$, so the large and persistent variations in $\bar{s}_{t}^{\mathrm{D}}-s_{t}$ and $\bar{s}_{t}^{\mathrm{P}}-s_{t}$ plotted in Figure 5 must reflect sizable changes in the either the expected future path for the interest differential or the risk premia. We examine these expectations with the aid of Figure 6.

The upper panel of Figure 6 plots the expected interest differentials term, $\hat{\mathbb{E}}_{t}^{N} \sum_{i=0}^{519}\left\{r_{t+i}-\hat{r}_{t+i}\right\}$ implied by the VAR-D and VAR-P model estimates. As the figure shows, both sets of estimates rise steadily between the start of 2006 and mid-200s, they then fluctuate through the world financial crisis until mid-20090. Thereafter they remain comparatively stable until 2012, when they begin to fall. The comparative stability in both sets of estimates away from the world financial crisis is consistent with the small values for the estimated variance ratios $\mathcal{R}_{r-\hat{r}}^{\mathrm{E}}(h)$ and $\mathcal{R}_{r-\hat{r}}^{\mathrm{U}}(h)$ discussed above. More importantly, the differences between the estimates implied by the VAR-P and VAR-D models are rather small and short-lived. So it appears that financial order flows rarely contained significant incremental information about future interest differentials.

Order flows play a much more significant role in driving expectations concerning the risk premium. The lower panel of Figure 6 plots the expected risk premia term, $\hat{\mathbb{E}}_{t}^{N} \sum_{i=0}^{519} \delta_{t+i}$ implied by the VAR-D and VAR$\mathrm{P}$ model estimates. Notice that on average the expected risk premium terms are negative, implying an long-term appreciation of the NOK of approximately 1.22 percent per year. This almost exactly offsets the average long-term depreciation of NOK implied the expected interest differential terms. As the plots clearly show, there are persistent periods where order flows convey significant incremental information concerning future risk premia beyond that contained in interest rates. In fact the differences between the expected risk premia terms largely coincide with the divergent estimates of the expected long-run depreciation plotted in the lower panel of Figure 5. The incremental information contained in order flows concerning future risk premia are the primary source of the differences in expected long-run depreciation rates.

The plots of the expected risk premium term also provide an interesting perspective on the factors driving the EURNOK rate from the beginning of the world financial crisis in mid-2007. Recall that the risk premia in our model identifies the expected $(\log )$ excess return to a Norwegian investor holding euro-area bonds. Thus expected risk premia term, $\hat{\mathbb{E}}_{t}^{N} \sum_{i=0}^{519} \delta_{t+i}$, represents the expected excess return to a Norwegian investor of rolling over a weekly euro-bond position for the next ten years. With this perspective, consider the movements in the expect risk premia terms around the hight of the world financial crisis. Panel B of Figure 6 shows that estimates of $\hat{\mathbb{E}}_{t}^{\mathrm{N}} \sum_{i=0}^{519} \delta_{t+i}$ incorporating order flow information diverge significantly from the VAR-P based estimates on three occasions: in the second half of 2007, at the end of 2008 and in mid-2009. In each instance, expected excess returns on euro-bond positions conditioned on order flow information fell well below the estimated conditioned on only public information. This pattern may be attributable to a fall in the perceived risk of holding euro-area rather than Norwegian short-term bonds. The estimates of $\hat{\mathbb{E}}_{t}^{\mathrm{N}} \sum_{i=0}^{519} \delta_{t+i}$ also diverge for over a year starting at the end of 2009. In this case expectations conditioned on order flow indicate that the perceived risks of holding euro-area bonds had risen relative to those associated with Norwegian bonds. Interestingly, this period coincides with the first-phase of the european debt crisis when the NOK was viewed as something of a "safe haven". Finally, the estimates of $\hat{\mathbb{E}}_{t}^{\mathrm{N}} \sum_{i=0}^{519} \delta_{t+i}$ diverge 
in the last two years of our sample period. Estimates conditioned on order flows first rise markedly in 2012, leading estimates conditioned only on public information. Thereafter, the estimates conditioned on order flow fall back but there is no significant change in the estimates conditioned on only public information.

Figure 6: Components of Expected long-run Depreciation Rates

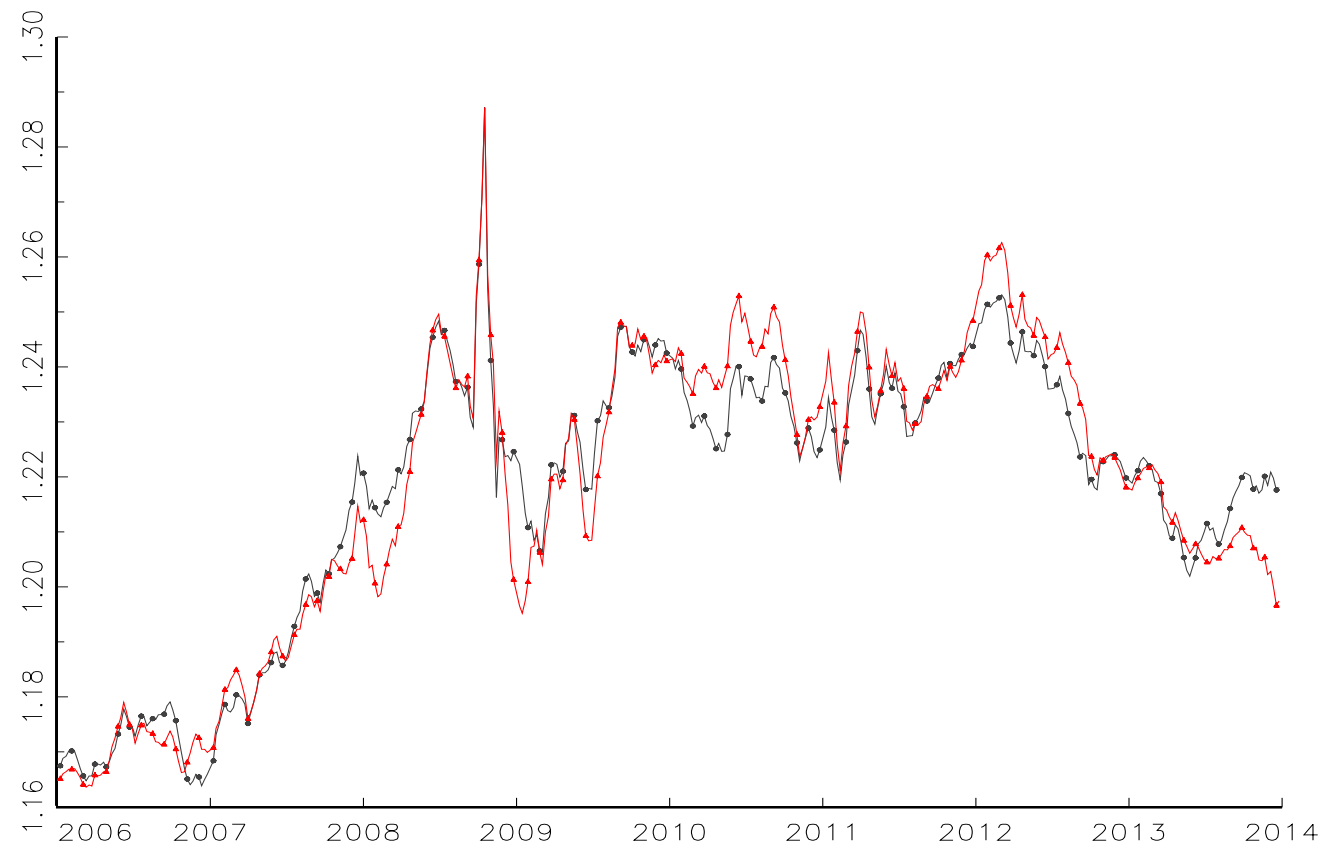

A: Expected interest differentials, $\hat{\mathbb{E}}_{t}^{\mathrm{N}} \sum_{i=0}^{519}\left\{r_{t+i}-\hat{r}_{t+i}\right\}$ for $\mathrm{N}=\mathrm{D}$ black with bullets; and for $\mathrm{N}=\mathrm{P}$, red with triangles. All series are 4 -week moving averages.

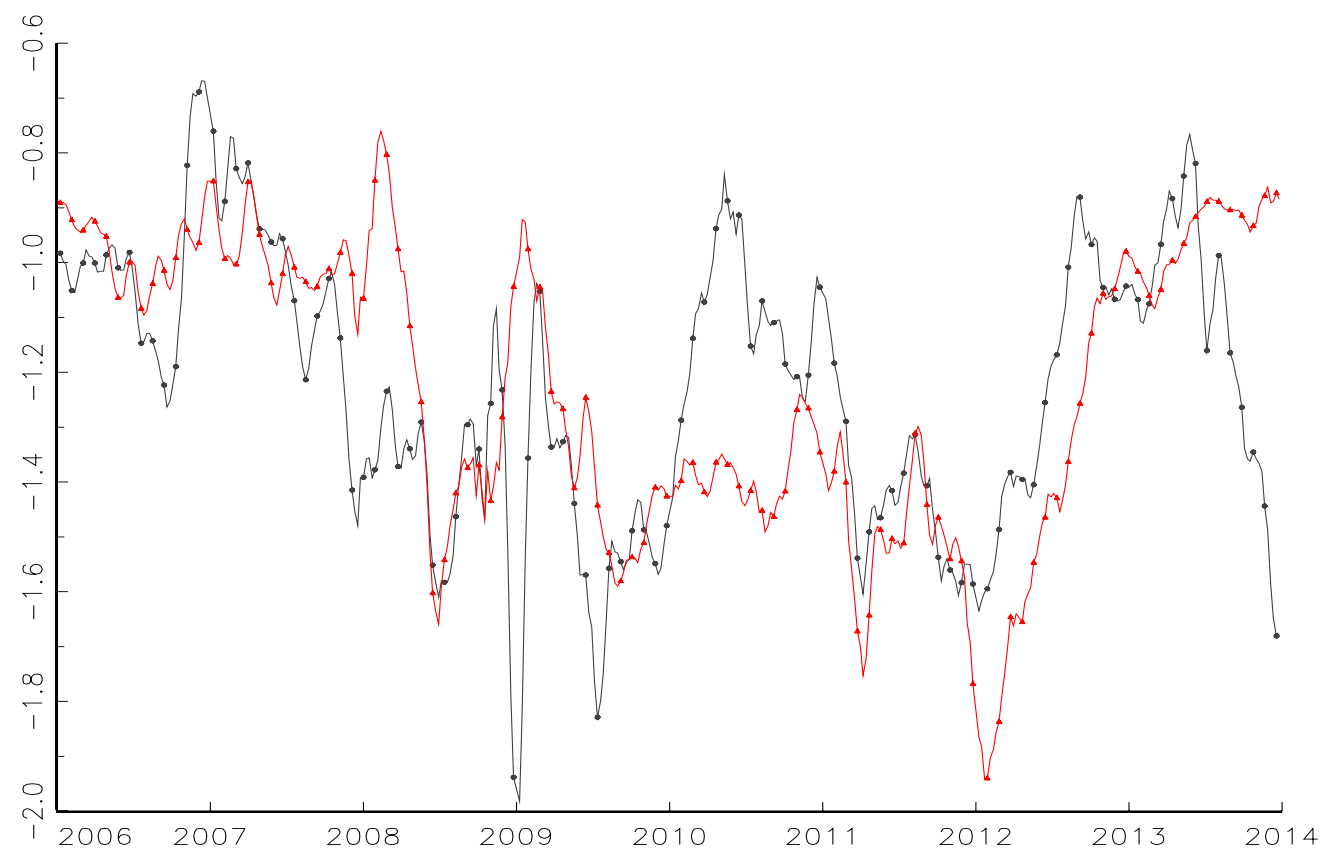

B: Expected risk premia, $\hat{\mathbb{E}}_{t}^{\mathrm{N}} \sum_{i=0}^{519} \delta_{t+i}$ for $\mathrm{N}=\mathrm{D}$ black with bullets; and for $\mathrm{N}=\mathrm{P}$, red with triangles. All series are 4 -week moving averages. 


\subsection{Robustness}

We examine the robustness of our results along three dimensions. First, we check that our variance ratio estimates are robust to the inclusion of additional lags in the VAR-P and VAR-D models. Second, we add the change in oil prices and Norwegian real estate prices to the set of macro variables included in both the VAR-P and VAR-D models. Third we examine how the variance ratios implied by the VAR-D model change when we use the order flows of different end-users to identify the error-correction term.

Increasing the number of lags in the VAR-P and VAR-D models make no appreciable difference to the results. Although the p-values associated with the Granger Causality tests in Table 6 are somewhat larger, the general forecasting patten is unchanged when we re-estimate the models with either two or three lags. More importantly, the variance ratios implied by these alternate specifications are essentially the same as those reported in Table 7 above.

Since our analysis focuses on the incremental information conveyed by end-user order flows (i.e., information that cannot be inferred from publicly observed macro variables), it is important to check that our findings are robust to inclusion of additional macro variables that may span more of the public information set than the interest rates and EURNOK exchange rate we include in our baseline VAR-D and VAR-P models. In the case of Norway, two variables are obvious candidates to consider for this purpose: oil and Norwegian real estate prices. Variations in both oil and real estate prices are correlated with changing macroeconomic and financial conditions within Norway (e.g., Bjørnland and Thorsrud, 2015; Bjørnland and Jacobsen, 2010), so insofar as these changing conditions are not reflected in the Norwegian term structure, the variables may span a portion of the public information set that was not covered in our baseline VAR-D and VAR-P models. In particular, it is possible that variations in both oil and real estate prices contain more precise information about future short-term Norwegian interest rates than could be inferred from the term spread alone. And, as a consequence, our baseline models understate the extent to which the EURNOK rate varies with expectations concerning future interest differentials.

Overall, we find that adding oil and real estate prices to the VAR-P and VAR-D models has very little impact on the variance ratio estimates. In VAR specifications with one to three lags we find no evidence that either variable has significant incremental forecasting power for any of the other variables in either the VAR-P or VAR-D models. Furthermore, the variance ratios computed from the VAR-D models are very similar to those reported in Table 7 . The one difference we do find is that the VAR-P models now produce slightly larger estimates of the $\mathcal{R}_{\delta}^{\mathrm{U}}(h)$ ratio: ranging from 0.06 to 0.15 as the horizon increases from 1 to 52 weeks. Thus shocks to oil and real estate prices produce larger revisions in expectations concerning future risk premia conditioned on public information than in our baseline VAR-P model. However, these estimates

continue to be statistically very different from those conditioned on order flows, consistent with the results in Table 7 .

Finally, we consider an alternative specification for the error-correction term included in the VAR-D model; one estimated using the cumulated order flow from the non-financial end-users. The correlation between this term and the term in the baseline model is 0.74 . We find that the variance ratio estimates from this alternative version of the VAR-D model are very similar to those in Table 7 at short horizons below 12 weeks. However, at longer horizons the information conveyed by the non-financial order flows have somewhat different characteristics. First, they contain more information about future depreciation rates. 
At one year the estimates of $\mathcal{R}_{\Delta s}^{\mathrm{E}}$ are approximately 0.4 , which is twice as large as the estimate based on the order flows of financial end-users. Second the estimates of $\mathcal{R}_{\delta}^{\mathrm{U}}$ are smaller (more negative) while the estimates of $\mathcal{R}_{\bar{s}}^{\cup}$ are larger, approximately -0.6 and 1.6, respectively at the one year horizon. Together, these results indicate that non-financial end-user order flows contain rather more long-term information about the level of the EURNOK and the risk-premia that the financial flows in our baseline model.

\section{Conclusion}

The results in this paper help clarify why order flows are empirically important proximate drivers of exchange rate dynamics. Our decomposition for the depreciation rate provides an information-based perspective on the role order flows plays in exchange rate determination that bridges the gap between traditional models that focus on macro fundamentals, and micro-based models that focus on currency trading. Empirically, our analysis of the EURNOK market based on this decomposition revealed several noteworthy findings. First, we found that order flows have significant (incremental) forecasting power for future depreciation rates over much longer (macro-relevant) horizons than reported in earlier research. Second, none of order flows' forecasting power reflects information they contain concerning the path of future interest differentials, but instead arises because flows carry information about future risk premia (excess returns). Finally, our historical decomposition reveals several periods around the world financial crisis and european debt crisis where the information conveyed by order flows concerning risk premia significantly affected the behavior of the EURNOK rate. 


\section{A Appendix (Not for Publication)}

\section{A.1 Variance Ratios}

Let $y_{t}^{\mathrm{P}}=\left[\begin{array}{llll}\Delta s_{t} & r_{t}-\hat{r}_{t} & s p r_{t} & \widehat{s p r}_{t}\end{array}\right]^{\prime}$ denote a vector containing publicly observed variables, containing the depreciation rate $\Delta s_{t}$, the interest differential, $r_{t}-\hat{r}_{t}$, the NOK and EUR spreads between long and shortterm nominal interest rates, $\operatorname{spr}_{t}$ and $\widehat{s p r}_{t}$. In some VAR specifications we also include other macro variables, such as the log change in oil prices and real estate prices in $y_{t}^{\mathrm{P}}$. The market information used by dealers is summarized in the vector $y_{t}^{\mathrm{M}}$. In the baseline specification, this vector only contains the error-correction term from the cointegrating regression of the log spot rate on cumulated order flows described in Section 3. We compute variance ratios from two VARs; one for $y_{t}^{\mathrm{P}}$ called the VAR-P, and one for $y_{t}^{\mathrm{D}}=\left[\begin{array}{lll}y_{t}^{\mathrm{P} \prime} & y_{t}^{\mathrm{M} \prime}\end{array}\right]^{\prime}$ called the VAR-D. Below we describe the calculations from the VAR-D, but those based on the VAR-P follow analogously.

Suppose we estimate a $k^{\prime}$ th order VAR for $y_{t}^{\mathrm{D}}$

$$
y_{t}^{\mathrm{D}}-\bar{y}^{\mathrm{D}}=a_{1}\left(y_{t-1}^{\mathrm{D}}-\bar{y}^{\mathrm{D}}\right)+a_{2}\left(y_{t-2}^{\mathrm{D}}-\bar{y}^{\mathrm{D}}\right)+\ldots . a_{k}\left(y_{t-k}^{\mathrm{D}}-\bar{y}^{\mathrm{D}}\right)+u_{t},
$$

where $\bar{y}^{\mathrm{D}}$ is the sample mean of $y_{t}^{\mathrm{D}}, a_{i}$ are estimated matrices of coefficients from each of the VAR equations, and $u_{t}$ is a vector of residuals. To compute the forecasts used in the variance ratios we write the estimated VAR in companion form as

$$
\left[\begin{array}{c}
y_{t}^{\mathrm{D}}-\bar{y}^{\mathrm{D}} \\
\vdots \\
\vdots \\
y_{t-k+1}^{\mathrm{D}}-y^{\mathrm{D}}
\end{array}\right]=\left[\begin{array}{cccc}
a_{1} & \cdots & \cdots & a_{k} \\
I & & & \\
& \ddots & & \\
& & I & 0
\end{array}\right]\left[\begin{array}{c}
y_{t-1}^{\mathrm{D}}-\bar{y}^{\mathrm{D}} \\
\vdots \\
\vdots \\
y_{t-k}^{\mathrm{D}}-\bar{y}^{\mathrm{D}}
\end{array}\right]+\left[\begin{array}{c}
u_{t} \\
0 \\
\vdots \\
0
\end{array}\right],
$$

or, more compactly,

$$
Y_{t}^{\mathrm{D}}-Y^{\mathrm{D}}=A\left(Y_{t-1}^{\mathrm{D}}-Y^{\mathrm{D}}\right)+U_{t} .
$$

Expectations of $Y_{t+h}^{\mathrm{D}}$ conditioned on $Y_{t}^{\mathrm{D}}$ are estimated from $(\mathrm{A} 1)$ as $\hat{\mathbb{E}}_{t}^{\mathrm{D}} Y_{t+h}^{\mathrm{D}}=Y^{\mathrm{D}}+\mathbb{E}\left[Y_{t+h}^{\mathrm{D}}-Y^{\mathrm{D}} \mid Y_{t}^{\mathrm{D}}-Y^{\mathrm{D}}\right]=$ $Y^{\mathrm{D}}+A^{h}\left(Y_{t}^{\mathrm{D}}-Y^{\mathrm{D}}\right)$, where $A^{h}$ denotes $h$ multiplications of the $A$ matrix. Expectations for an individual variable $\varkappa_{t}$ in $Y_{t}^{\mathrm{D}}$ are computed as $\hat{\mathbb{E}}_{t}^{\mathrm{D}} \varkappa_{t+h}=\iota_{\varkappa} Y^{\mathrm{D}}+\iota_{\varkappa} A^{h}\left(Y_{t}^{\mathrm{D}}-Y^{\mathrm{D}}\right)$, where the vector $\iota_{\varkappa}$ selects $\varkappa_{t}$ from $Y_{t}^{\mathrm{D}}$.

We can now compute the various components found in the variance ratios as follows: Estimates of the expected depreciation rate are given by

$$
\hat{\mathbb{E}}_{t}^{\mathrm{D}} \Delta^{h} s_{t+h}=\hat{\mathbb{E}}_{t}^{\mathrm{D}} \sum_{i=1}^{h} \Delta s_{t+i}=\imath_{s}(I-A)^{-1}\left(I-A^{h}\right) A\left(Y_{t}^{\mathrm{D}}-Y^{\mathrm{D}}\right)+h \imath_{s} Y^{\mathrm{D}} .
$$


These expectations comprise forecasts for future interest differentials and risk premia:

$$
\begin{aligned}
\hat{\mathbb{E}}_{t}^{\mathrm{D}} \sum_{i=0}^{h-1}\left(r_{t+i}-\hat{r}_{t+i}\right) & =\imath_{r} \sum_{i=0}^{h-1} A^{i}\left(Y_{t}^{\mathrm{D}}-Y^{\mathrm{D}}\right)+h \imath_{r} Y^{\mathrm{D}} \\
& =\imath_{r}(I-A)^{-1}\left(I-A^{h}\right)\left(Y_{t}^{\mathrm{D}}-Y^{\mathrm{D}}\right)+h \imath_{r} Y^{\mathrm{D}} \quad \text { and } \\
\hat{\mathbb{E}}_{t}^{\mathrm{D}} \sum_{i=0}^{h-1} \delta_{t+i} & =\mathbb{E}_{t}^{\mathrm{D}} \Delta^{h} s_{t+h}-\mathbb{E}_{t}^{\mathrm{D}} \sum_{i=0}^{h-1}\left(r_{t+i}-\hat{r}_{t+i}\right) \\
& =\left\{\imath_{s}(I-A)^{-1}\left(I-A^{h}\right) A-\imath_{r}(I-A)^{-1}\left(I-A^{h}\right)\right\}\left(Y_{t}^{\mathrm{D}}-Y^{\mathrm{D}}\right)+h\left(\imath_{s}-\imath_{r}\right) Y^{\mathrm{D}} .
\end{aligned}
$$

Next, let $\Sigma_{y}^{\mathrm{D}}$ denote the covariance matrix for $Y_{t}^{\mathrm{D}}$ computed as the solution to $\Sigma_{y}^{\mathrm{D}}=A \Sigma_{y}^{\mathrm{D}} A^{\prime}+\Sigma_{u}$, where $\Sigma_{u}$ is the estimated covariance matrix for $U_{t}$. Equations (A2) - (A4) imply that

$$
\begin{aligned}
& \mathbb{V}\left(\hat{\mathbb{E}}_{t}^{\mathrm{D}} \Delta^{h} s_{t+h}\right)=\imath_{s}(I-A)^{-1}\left(I-A^{h}\right) A \Sigma_{y y}^{\mathrm{D}} A^{\prime}\left(I-A^{h}\right)^{\prime}\left[(I-A)^{-1}\right]^{\prime} \imath_{s}^{\prime}, \\
& \left(\left(\hat{\mathbb{E}}_{t}^{\mathrm{D}} \sum_{i=0}^{h-1}\left(r_{t+i}-\hat{r}_{t+i}\right), \hat{\mathbb{E}}_{t}^{\mathrm{D}} \Delta^{h} s_{t+h}\right)\right)=\imath_{r}(I-A)^{-1}\left(I-A^{h}\right) \Sigma_{y}^{\mathrm{D}} A^{\prime}\left(I-A^{h}\right)^{\prime}\left[(I-A)^{-1}\right]^{\prime} \imath_{s}^{\prime}, \quad \text { and } \\
& \mathbb{C V}\left(\hat{\mathbb{E}}_{t}^{\mathrm{D}} \sum_{i=0}^{h-1} \delta_{t+i}, \hat{\mathbb{E}}_{t}^{\mathrm{D}} \Delta^{h} s_{t+h}\right)=\left\{\imath_{s}(I-A)^{-1}\left(I-A^{h}\right) A-\imath_{r}(I-A)^{-1}\left(I-A^{h}\right)\right\} \\
& \times \Sigma_{y}^{\mathrm{D}} A^{\prime}\left(I-A^{h}\right)^{\prime}\left[(I-A)^{-1}\right]^{\prime} \imath_{s}^{\prime}
\end{aligned}
$$

These terms are used to compute the ratios in (6).

The ratios in (7) require estimates of the components that comprise unexpected depreciation rates. Using the estimates of VAR-D we have

$$
\begin{aligned}
\Delta^{h} s_{t+h}-\hat{\mathbb{E}}_{t}^{\mathrm{D}} \Delta^{h} s_{t+h} & =\sum_{i=1}^{h}\left(\Delta s_{t+i}-\Delta s-\mathbb{E}_{t}^{\mathrm{D}}\left(\Delta s_{t+i}-\Delta s\right)\right) \\
& =\imath_{s} \sum_{i=1}^{h}\left(Y_{t+i}^{\mathrm{D}}-Y^{\mathrm{D}}-A^{i}\left(Y_{t}^{\mathrm{D}}-Y^{\mathrm{D}}\right)\right) \\
& =\imath_{s}(I-A)^{-1} \sum_{i=1}^{h}\left(I-A^{h+1-i}\right) U_{t+i} .
\end{aligned}
$$

The estimated contribution from news concerning future interest differentials is given by

$$
\begin{aligned}
\left(\hat{\mathbb{E}}_{t+h}^{\mathrm{D}}-\hat{\mathbb{E}}_{t}^{\mathrm{D}}\right) \sum_{i=h}^{H+h-1}\left(\hat{r}_{t+i}-r_{t+i}\right) & =\left(\hat{\mathbb{E}}_{t+h}^{\mathrm{D}}-\hat{\mathbb{E}}_{t}^{\mathrm{D}}\right) \sum_{i=h}^{H+h-1}\left(\hat{r}_{t+i}-r_{t+i}-(\hat{r}-r)\right) \\
& =-l_{r}(I-A)^{-1}\left(I-A^{H}\right)\left(\left(Y_{t+h}^{\mathrm{D}}-Y^{\mathrm{D}}\right)-A^{h}\left(Y_{t}^{\mathrm{D}}-Y^{\mathrm{D}}\right)\right) \\
& =-l_{r}(I-A)^{-1}\left(I-A^{H}\right)\left(U_{t+h}+A U_{t+h-1}+\ldots . A^{h-1} U_{t+1}\right) .
\end{aligned}
$$


To compute the contribution of news concerning the future risk premium, first note that

$$
\bar{s}_{t}-s_{t}=\hat{\mathbb{E}}_{t}^{\mathrm{D}} s_{t+H}-s_{t}=\hat{\mathbb{E}}_{t}^{\mathrm{D}} \sum_{i=1}^{H} \Delta s_{t+i}=\imath_{s}(I-A)^{-1}\left(I-A^{H}\right) A\left(Y_{t+h}^{\mathrm{D}}-Y^{\mathrm{D}}\right)+H \imath_{s} Y^{\mathrm{D}} .
$$

Combining this expression with $(3 \mathrm{~b})$ gives

$$
\begin{aligned}
\left(\hat{\mathbb{E}}_{t+h}^{\mathrm{D}}-\hat{\mathbb{E}}_{t}^{\mathrm{D}}\right) \sum_{i=h}^{H+h-1} \delta_{t+i} & =\left(\bar{s}_{t+h}-s_{t+h}\right)-\hat{\mathbb{E}}_{t}^{\mathrm{D}}\left(s_{t+h}-\bar{s}_{t+h}\right)-\left(\hat{\mathbb{E}}_{t+h}^{\mathrm{D}}-\hat{\mathbb{E}}_{t}^{\mathrm{D}}\right) \sum_{i=h}^{H+h-1}\left(r_{t+i}-\hat{r}_{t+i}\right) \\
& =\left(\hat{\mathbb{E}}_{t+h}^{\mathrm{D}}-\hat{\mathbb{E}}_{t}^{\mathrm{D}}\right) \sum_{i=1}^{H} \Delta s_{t+h+i}-\left(\hat{\mathbb{E}}_{t+h}^{\mathrm{D}}-\hat{\mathbb{E}}_{t}^{\mathrm{D}}\right) \sum_{i=h}^{H+h-1}\left(r_{t+i}-\hat{r}_{t+i}\right) \\
& =\left(\hat{\mathbb{E}}_{t+h}^{\mathrm{D}}-\hat{\mathbb{E}}_{t}^{\mathrm{D}}\right) \sum_{i=1}^{H}\left(\Delta s_{t+h+i}-\Delta s\right)-\left(\hat{\mathbb{E}}_{t+h}^{\mathrm{D}}-\hat{\mathbb{E}}_{t}^{\mathrm{D}}\right) \sum_{i=h}^{H+h-1}\left(r_{t+i}-\hat{r}_{t+i}-(\hat{r}-r)\right) \\
& =\left\{\imath_{s}(I-A)^{-1}\left(I-A^{H}\right) A-l_{r}(I-A)^{-1}\left(I-A^{H}\right)\right\}\left(\left(Y_{t+h}^{\mathrm{D}}-Y^{\mathrm{D}}\right)-A^{h}\left(Y_{t}^{\mathrm{D}}-Y^{\mathrm{D}}\right)\right) \\
& =\left\{\imath_{s}(I-A)^{-1}\left(I-A^{H}\right) A-l_{r}(I-A)^{-1}\left(I-A^{H}\right)\right\}\left(U_{t+h}+A U_{t+h-1}+\ldots . . A^{h-1} U_{t+1}\right) .
\end{aligned}
$$

The contribution from news concerning the long-run spot rate is therefore

$$
\begin{aligned}
\bar{s}_{t+h}-\hat{\mathbb{E}}_{t}^{\mathrm{D}} \bar{s}_{t+h} & =s_{t+h}-\hat{\mathbb{E}}_{t}^{\mathrm{D}} s_{t+h}+\left(\hat{\mathbb{E}}_{t+h}^{\mathrm{D}}-\hat{\mathbb{E}}_{t}^{\mathrm{D}}\right) \sum_{i=1}^{H} \Delta s_{t+h+i} \\
& =\sum_{i=1}^{h}\left(\Delta s_{t+i}-\hat{\mathbb{E}}_{t}^{\mathrm{D}} \Delta s_{t+i}\right)+\left(\hat{\mathbb{E}}_{t+h}^{\mathrm{D}}-\hat{\mathbb{E}}_{t}^{\mathrm{D}}\right) \sum_{i=1}^{H} \Delta s_{t+h+i} \\
& =\iota_{s} \sum_{i=1}^{h}\left(Y_{t+i}^{\mathrm{D}}-Y^{\mathrm{D}}-A^{i}\left(Y_{t}^{\mathrm{D}}-Y^{\mathrm{D}}\right)\right)+\imath_{s}(I-A)^{-1}\left(I-A^{H}\right) A\left(Y_{t+h}^{\mathrm{D}}-Y^{\mathrm{D}}-A^{h}\left(Y_{t}^{\mathrm{D}}-Y^{\mathrm{D}}\right)\right) \\
& =\iota_{s}(I-A)^{-1} \sum_{i=1}^{h}\left(I-A^{h+1-i}\right) U_{t+i}+\imath_{s}(I-A)^{-1}\left(I-A^{H}\right) A\left(U_{t+h}+A U_{t+h-1}+\ldots . . A^{h-1} U_{t+1}\right) \\
& =\iota_{s}(I-A)^{-1} \sum_{i=1}^{h}\left\{\left(I-A^{h+1-i}\right)+\left(I-A^{H}\right) A^{h+1-i}\right\} U_{t+i} \\
& =\iota_{s}(I-A)^{-1} \sum_{i=1}^{h}\left\{I-A^{H} A^{h+1-i}\right\} U_{t+i} .
\end{aligned}
$$

With equations (A8) - (A11) we can compute

$$
\mathbb{V}\left(s_{t+h}-\hat{\mathbb{E}}_{t}^{\mathrm{D}} s_{t+h}\right)=\imath_{s}(I-A)^{-1}\left\{\sum_{i=1}^{h}\left(I-A^{h+1-i}\right) \Sigma_{u}\left(I-A^{h+1-i}\right)\right\}\left[(I-A)^{-1}\right]^{\prime} l_{s}^{\prime},
$$




$$
\begin{aligned}
& \mathbb{C V}\left(\left(\hat{\mathbb{E}}_{t+h}^{\mathrm{D}}-\hat{\mathbb{E}}_{t}^{\mathrm{D}}\right) \sum_{i=h}^{H+h-1}\left(\hat{r}_{t+i}-r_{t+i}\right), s_{t+h}-\hat{\mathbb{E}}_{t}^{\mathrm{D}} s_{t+h}\right)=-l_{r}(I-A)^{-1}\left(I-A^{H}\right) \times\left\{\sum_{i=1}^{h}\left(A^{h-i}\right) \Sigma_{u}\left(I-A^{h+1-i}\right)^{\prime}\right\}\left[(I-A)^{-1}\right]^{\prime} l_{s}^{\prime}, \quad(\mathrm{A} 13) \\
& \times\left\{\sum_{i=1}^{h}\left(A^{h-i}\right) \Sigma_{u}\left(I-A^{h+1-i}\right)^{\prime}\right\}\left[(I-A)^{-1}\right]^{\prime} l_{s}^{\prime}, \quad(\mathrm{A} 14) \\
& \mathbb{C V}\left(\left(\hat{\mathbb{E}}_{t+h}^{\mathrm{D}}-\hat{\mathbb{E}}_{t}^{\mathrm{D}}\right) \sum_{i=h}^{H+h-1} \delta_{t+i}, s_{t+h}-\hat{\mathbb{E}}_{t}^{\mathrm{D}} s_{t+h}\right)=\left\{\imath_{s}(I-A)^{-1}\left(I-A^{H}\right) A-l_{r}(I-A)^{-1}\left(I-A^{H}\right)\right\} \\
& \mathbb{C V}\left(\bar{s}_{t+h}-\hat{\mathbb{E}}_{t}^{\mathrm{D}} \bar{s}_{t+h}, s_{t+h}-\hat{\mathbb{E}}_{t}^{\mathrm{D}} s_{t+h}\right)=\imath_{s}(I-A)^{-1}\left\{\sum_{i=1}^{h}\left(I-A^{H} A^{h+1-i}\right) \Sigma_{u}\left(I-A^{h+1-i}\right)^{\prime}\right\}\left[(I-A)^{-1}\right]^{\prime} l_{s}^{\prime} .
\end{aligned}
$$

The ratios in (7) are computed from these moments.

Finally, the ratios in (5) are computed from (A5) and (A12) using the facts that

$$
\begin{gathered}
\mathbb{C V}\left(\hat{\mathbb{E}}_{t}^{\mathrm{N}} \Delta^{h} s_{t+h}, \Delta^{h} s_{t+h}\right)=\mathbb{V}\left(\hat{\mathbb{E}}_{t}^{\mathrm{N}} \Delta^{h} s_{t+h}\right), \\
\mathbb{C V}\left(s_{t+h}-\hat{\mathbb{E}}_{t}^{\mathrm{N}} s_{t+h}, \Delta^{h} s_{t+h}\right)=\mathbb{V}\left(s_{t+h}-\hat{\mathbb{E}}_{t}^{\mathrm{N}} s_{t+h}\right) \quad \text { and } \\
\mathbb{V}\left(\Delta^{h} s_{t+h}\right)=\mathbb{V}\left(\hat{\mathbb{E}_{t}^{\mathrm{D}}} \Delta^{h} s_{t+h}\right)+\mathbb{V}\left(s_{t+h}-\hat{\mathbb{E}}_{t}^{\mathrm{D}} s_{t+h}\right) .
\end{gathered}
$$

\section{A.2 Historical Decomposition}

We compute the historical decomposition of the spot rate

$$
s_{t}=\hat{\mathbb{E}}_{t}^{\mathrm{D}} \sum_{i=0}^{H-1}\left\{\hat{r}_{t+i}-r_{t+i}\right\}-\hat{\mathbb{E}}_{t}^{\mathrm{D}} \sum_{i=0}^{H-1} \delta_{t+i}+\hat{\mathbb{E}}_{t}^{\mathrm{D}} s_{t+H}
$$

from the estimates of the VAR-D as:

$$
\begin{aligned}
\hat{\mathbb{E}}_{t}^{\mathrm{D}} \sum_{i=0}^{H-1}\left\{\hat{r}_{t+i}-r_{t+i}\right\} & =-\imath_{r} \sum_{i=0}^{H-1} A^{i}\left(Y_{t}^{\mathrm{D}}-Y^{\mathrm{D}}\right)+H \imath_{r} Y^{\mathrm{D}} \\
& =-\imath_{r}(I-A)^{-1}\left(I-A^{H}\right)\left(Y_{t}^{\mathrm{D}}-Y^{\mathrm{D}}\right)-H \iota_{r} Y^{\mathrm{D}},
\end{aligned}
$$




$$
\begin{aligned}
\hat{\mathbb{E}}_{t}^{\mathrm{D}} \sum_{i=0}^{H-1} \delta_{t+i} & =\hat{\mathbb{E}}_{t}^{\mathrm{D}} \sum_{i=0}^{H-1}\left\{\hat{r}_{t+i}-r_{t+i}\right\}+\hat{\mathbb{E}}_{t}^{\mathrm{N}} s_{t+H}-s_{t} \\
& =\hat{\mathbb{E}}_{t}^{\mathrm{D}} \sum_{i=0}^{H-1}\left\{\hat{r}_{t+i}-r_{t+i}\right\}+\hat{\mathbb{E}}_{t}^{\mathrm{D}} \sum_{i=1}^{H} \Delta s_{t+i}-\hat{\mathbb{E}}_{t}^{\mathrm{D}} \sum_{i=0}^{H-1}\left\{r_{t+i}-\hat{r}_{t+i}\right\} \\
& =\left\{\imath_{s}(I-A)^{-1}\left(I-A^{H}\right) A-\imath_{r}(I-A)^{-1}\left(I-A^{H}\right)\right\}\left(Y_{t}^{\mathrm{D}}-Y^{\mathrm{D}}\right)+H\left(\imath_{s}-\imath_{r}\right) Y^{\mathrm{D}}
\end{aligned}
$$

and

$$
\hat{\mathbb{E}}_{t}^{\mathrm{N}} s_{t+H}=s_{t}+\mathbb{E}_{t}^{\mathrm{D}} \sum_{i=1}^{H} \Delta s_{t+i}=s_{t}+\imath_{s}(I-A)^{-1}\left(I-A^{H}\right) A\left(Y_{t}^{\mathrm{D}}-Y^{\mathrm{D}}\right)+H \imath_{s} Y^{\mathrm{D}} .
$$

The decomposition based on the expectations conditioned on public information

$$
s_{t}=\hat{\mathbb{E}}_{t}^{\mathrm{P}} \sum_{i=0}^{H-1}\left\{\hat{r}_{t+i}-r_{t+i}\right\}-\hat{\mathbb{E}}_{t}^{\mathrm{P}} \sum_{i=0}^{H-1} \delta_{t+i}+\hat{\mathbb{E}}_{t}^{\mathrm{P}} s_{t+H}
$$

are computed from VAR-P in an analogous manner. 


\section{References}

Buønnes, G. H., D. Rime, and H. O. A. Solheim (2005): "Liquidity Provision in the Overnight Foreign Exchange Market," Journal of International Money \& Finance, 24(2), 177-198. 3

BJørnland, H. C., and D. H. Jacobsen (2010): "The role of house prices in the monetary policy transmission mechanism in small open economies," Journal of Financial Stability, 6, 218-229. 4.4

Bjørnland, H. C., and L. A. Thorsrud (2015): "Boom or gloom? Examining the Dutch disease in two-speed economies," Economic Journal, Forthcoming. 4.4

Chinn, M. (2012): "Macro Approaches to Foreign Exchange Determination," in Handbook of Exchange Rates, ed. by J. James, I. Marsh, and L. Sarno, pp. 45-71. Wiley Online Library. 1

Chinn, M. D., And M. J. Moore (2011): "Order Flow and the Monetary Model of Exchange Rates: Evidence from a Novel Data Set," Journal of Money, Credit \& Banking, 43(8), 1599-1624. 3

Engel, C., N. C. Mark, and K. D. West (2008): "Exchange Rate Models Are Not As Bad As You Think," in NBER Macroeconomics Annual 2007, Volume 22, pp. 381-441. University of Chicago Press. 1

Engel, C., And K. West (2006): "Taylor Rules and the Deutschmark-Dollar Real Exchange Rate," Journal of Money, Credit \& Banking, 38(5), 1175-1194. 1

Evans, M. D. D. (2010): "Order Flows and The Exchange Rate Disconnect Puzzle," Journal of International Economics, 80(1), 58-82. 1

(2011): Exchange-Rate Dynamics, Princeton Series in International Finance. 1, 2, 2, 3

- (2012): "Exchange-Rate Dark Matter," IMF Working Paper 12/66, International Monetary Fund. 4.2

Evans, M. D. D., And R. K. Lyons (2002): "Order flow and exchange rate dynamics," Journal of Political Economy, 110(1), 170-180. 2, 3

- (2005a): "Do Currency Markets Absorb News Quickly?," Journal of International Money E3 Finance, 24(6), 197-217. 3

(2005b): "Meese-Rogoff Redux: Micro-Based Exchange-Rate Forecasting," American Economic Review. Papers \& Proceedings, 95(2), 405-414. 2, 3, 4.2

- (2013): "Exchange Rate Fundamentals and Order Flow," Quarterly Journal of Finance, 02(04), 1250018. $1,3,3,3$

Evans, M. D. D., And D. Rime (2012): "Micro Approaches to Foreign Exchange Determination," in Handbook of Exchange Rates, ed. by J. James, I. Marsh, and L. Sarno. John Wiley \& Sons. 3

Froot, K. A., and T. Ramadorai (2005): "Currency Returns, Intrinsic Value, and Institutional-Investor Flows," Journal of Finance, 60(3), 1535-1566. 1, 3 
King, M., L. Sarno, and E. Sojli (2010): "Timing exchange rates using order flow: The case of the Loonie," Journal of Banking \& Finance, 34(12), 2917-2928. 1, 2, 8, 4.2

Mark, N. (2009): "Changing Monetary Policy Rules, Learning, and Real Exchange Rate Dynamics," Journal of Finance $\mathcal{E}$ Banking, 41(6), 1047-1070. 1

Marsh, I. W., and C. O'Rourke (2005): "Customer Order Flow and Exchange Rate Movements: Is There Really Information Content?," Working paper, Cass Business School. 3, 3

Meyer, E., And J. SkJelvik (2006): "Statistics on foreign exchange transactions - new insight into foreign exchange markets," Norges Bank Economic Bulletin, (2/06), 80-88. 3, 7

Osler, C. L. (2009): "Market Microstructure, Foreign Exchange," in Encyclopedia of Complexity and System Science, ed. by R. A. Meyers, pp. 5404-5438. Springer, New York. 3

Rime, D., L. Sarno, and E. Sojli (2010a): "Exchange Rate Forecasting, Order Flow and Macroeconomic Information," Journal of International Economics, 80(1), 72-88. 1, 3

International Economics, $80(1), 72-88.4 .2$

Rossi, B. (2013): "Exchange Rate Predictability," Journal of Economic Literature, 51(4), 1063-1119. 4.2 